\title{
Electric Vehicle Longitudinal Stability Control Based on a New Multimachine Nonlinear Model Predictive Direct Torque Control
}

\author{
M'hamed Sekour, Kada Hartani, and Abdelkader Merah \\ Electrotechnical Engineering Laboratory, Tahar Moulay University, Saida, Algeria \\ Correspondence should be addressed to Abdelkader Merah; merah_aek@yahoo.fr
}

Received 3 March 2017; Accepted 28 August 2017; Published 12 November 2017

Academic Editor: Xing Wu

Copyright (C) 2017 M'hamed Sekour et al. This is an open access article distributed under the Creative Commons Attribution License, which permits unrestricted use, distribution, and reproduction in any medium, provided the original work is properly cited.

In order to improve the driving performance and the stability of electric vehicles (EVs), a new multimachine robust control, which realizes the acceleration slip regulation (ASR) and antilock braking system (ABS) functions, based on nonlinear model predictive (NMP) direct torque control (DTC), is proposed for four permanent magnet synchronous in-wheel motors. The in-wheel motor provides more possibilities of wheel control. One of its advantages is that it has low response time and almost instantaneous torque generation. Moreover, it can be independently controlled, enhancing the limits of vehicular control. For an EV equipped with four in-wheel electric motors, an advanced control may be envisaged. Taking advantage of the fast and accurate torque of in-wheel electric motors which is directly transmitted to the wheels, a new approach for longitudinal control realized by ASR and ABS is presented in this paper. In order to achieve a high-performance torque control for EVs, the NMP-DTC strategy is proposed. It uses the fuzzy logic control technique that determines online the accurate values of the weighting factors and generates the optimal switching states that optimize the EV drives' decision. The simulation results built in Matlab/Simulink indicate that the EV can achieve high-performance vehicle longitudinal stability control.

\section{Introduction}

One of the most fundamental differences between electric vehicles (EVs) and the conventional internal combustion engine vehicles (ICEVs) is that EVs are fully or partially driven by electric motors, which can bring about a lot of unique advantages for dynamic traction control [1]. With the superior control performance of electric motors compared to ICEVs, EVs could be not only clean, but also able to achieve higher levels of safety and handling $[1,2]$.

The distinct advantages of well-controlled electric motors may include fast torque response $[1,3]$, simple dynamics $[1,4]$, easy-to-obtain torque feedback (the torque generated from electric motors is proportional to the motor current for industrial applications [5, 6]), capability of generating both traction and braking forces (regenerative braking during deceleration can be realized using electric motors $[7,8]$ ), and easy-to-implement distributed in-wheel motor systems (electric motors usually have compact sizes but powerful and flexible outputs, which can improve dynamic control stability $[4,9,10]$, energy efficiency [11], and fun to drive [12]).

Antilock braking system (ABS) and traction control (TC) system represent both classic effective approaches to longitudinal vehicle dynamics control. The primary functions of these systems can be formulated as follows in accordance with reference literature [13]: ABS is a system that prevents the locking of wheels during braking in order to achieve high brake performance while simultaneously maintaining vehicle stability. TC is a system that prevents the skidding of wheels during take-off and acceleration. As for TC, an alternative term is also known from the technical literature: acceleration slip regulation (ASR).

In the last years, several techniques based on nonlinear control have been applied in wheel slip control research. In [14], a model control structure named the behavior model control (BMC), well adapted to the nonlinear systems, which 
realizes the wheel slip control, is used to solve the nonlinear problem of adhesion. As a result, the skid phenomenon disappeared and the stability of the vehicle was ensured. A fuzzy logic slip control system for EVs with in-wheel motors was introduced in [15]. Reference [16] proposed a nonlinear wheel slip control algorithm which ensures the stability in a closed loop. Reference [17] proposed a fuzzy logic antiskid control structure which is used to overcome the main problem of powertrain systems in the wheel road adhesion characteristic. This structure can prevent vehicle slipping and show good vehicle stability on a curved path. In [18], a wheel slip controller based on sliding mode framework is proposed. A nonlinear model predictive controller for wheel slip control of EV equipped with four in-wheel motors is studied in [19]. The research object in [20] is to study the acceleration slip regulation (ASR) control for two-wheel independent driving EV based on dynamic torque distribution.

The loss of adherence of one of the four wheels is likely to destabilize the vehicle, which needs to be solved either in traction or in braking mode. In order to improve the safety and dynamic performance of electric vehicles and prevent the wheel from locking or slipping when braking or accelerating, it is necessary to control the slip ratio of each wheel in the stable region. Combining the two functions ASR and $\mathrm{ABS}$, this paper presented a new longitudinal control for the electric vehicle equipped with four PMS in-wheel motors. A main significant advantage of this proposed longitudinal control is that it can act as an antilock braking system (ABS) by preventing the wheels from getting locked during braking and as acceleration slip regulation (ASR) by preventing the wheels from slipping during acceleration. Moreover, using the wheel angular acceleration and the slip ratio, a fuzzy ASR/ABS controller is designed; based on the experimental road, the vehicle will achieve a good acceleration performance when the slip ratio is maintained within the optimal range, and this is done by adjusting the correspondent PMS in-wheel motor torque dynamically. Compared with previous studies, the proposed longitudinal control, which has been verified under accelerating maneuvers and braking maneuvers, proves its robustness and the longitudinal slip ratio of each wheel can reach quickly the optimal longitudinal slip ratio.

Permanent magnet synchronous motors (PMSMs) have been considered the potential candidate for electric vehicle (EV) applications due to their high power density, low maintenance cost, effectiveness, high torque ratio, wide speed range, dynamic qualities, and robust operations [21, 22]. Focusing on the EV-traction application, a fast and robust torque response of the PMSM is required in a wide speed range to meet the instantaneous torque demand commanded by the driver.

Examining the control structure for EV traction, direct torque control (DTC) for traction means the torque control of a traction motor (e.g., a permanent magnet synchronous motor (PMSM) drive). Thus, the DTC strategy for PMSM drive is the right candidate for the high-performance control to meet the EV-traction requirements. However, high torque and flux ripples and variable switching can be observed because of an included switching table, and these are some of its drawbacks [23].

To overcome these drawbacks, improved DTC schemes have been reported in the literature [21, 22, 24, 25]. In order to obtain fast and robust torque response and to solve the problems caused by the torque ripple affecting the mechanical transmission of the electric traction chain, the basic DTC strategy can be integrated with a space vector modulation (SVM) [26-28]. In this case, the torque and stator flux are regulated more accurately with a fixed switching frequency. Other methods based on fuzzy logic control have been adopted to ensure good performance [21]. A fuzzy direct torque control (FDTC) based on space vector modulation, which uses the stator flux and the torque errors through two fuzzy logic controllers to generate a voltage space vector (reference voltage), is to provide the inverter switching states.

Model predictive control (MPC) is now regarded as one of the most robust control strategies. Several variants of MPC have been proposed in the technical literature. They are based on the optimization of a cost function consisting of the difference between the actual output and the trajectory to be tracked [29]. Several applications have employed the discretetime linear model (DTLM) for predictive control. It allows a fast analytical solution of the optimization problem. The predictive control of the PMSM based on the DTLM has been described in [30], where the load torque is considered as a known disturbance.

Recently, model predictive control (MPC) strategy, which can take into account the plant constraints and nonlinearities with multiple inputs/outputs and handle them in a proper way, has been reported [31]. It generally has an optimal, naturally robust, and simple structure. Thus, it can be combined with the basic DTC scheme to synthesize a highperformance controller for the PMSM drives. Unlike the basic DTC or FOC with SVM, the MP-DTC strategy is based on the optimal control approach. Having the cost function designed to minimize the torque and flux control errors [32], optimized switching states can be generated.

In this paper, we propose a direct torque control (DTC) strategy based on nonlinear model predictive (NMP) control for the EV traction, using PMS in-wheel drive. Given the EV system dynamics and an objective cost function, the proposed NMP-DTC strategy uses the fuzzy logic control technique to determine online the accurate values of the weighting factors (i.e., penalty factors) and generate the optimal switching states that optimize the EV drives' decision.

Some applications in the field of electrical drives require using several electric machines and many static converters that have an important place among electromechanical systems. These systems are called multimachine multiconverter systems (MMSs) [33]. When several machines are associated to carry out cooperative functions (the contribution of the four-machine efforts for the advancement of an electric vehicle, in our case), the embedded mass can still be reduced by sharing power electronics. Until recently, together with the development of semiconductor technology and the introduction of powerful microprocessor and power electronic devices, among others, systems which began to be more interesting and which include multisynchronous machines 


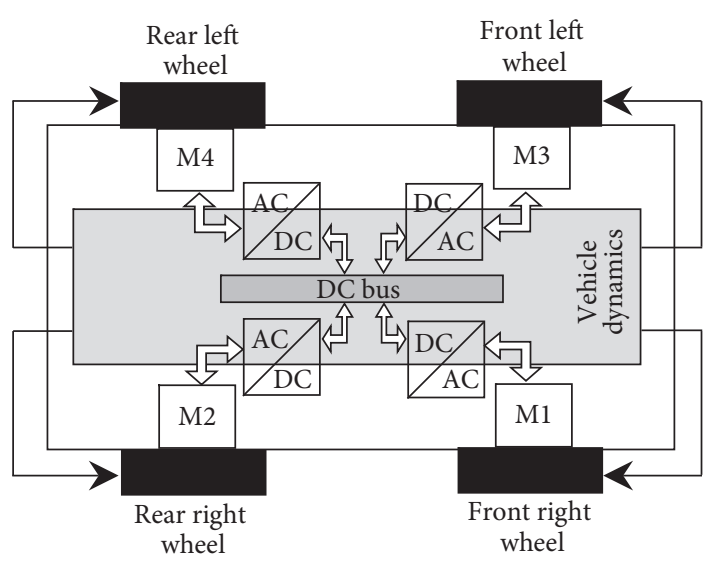

(a)

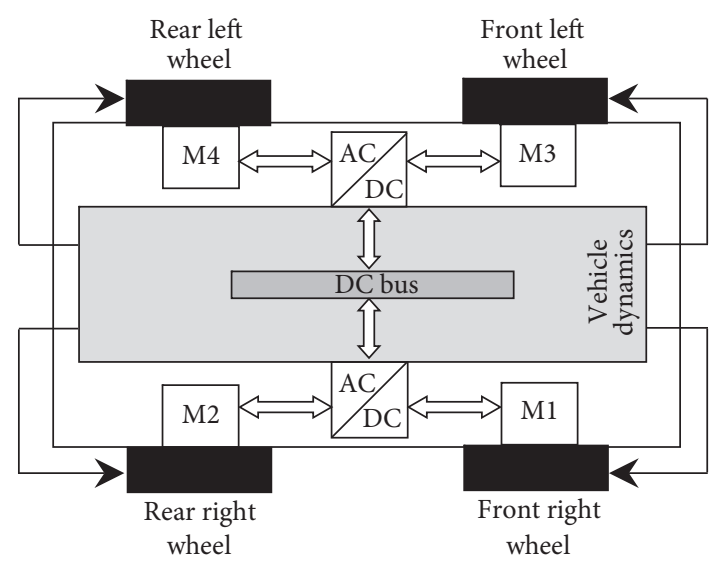

(b)

FIGURE 1: Structure of EV traction with (a) four and (b) two inverters.

(especially PMSMs) are driven by a single inverter. Our work is developed in this context. The power reduced structures based on power electronics are able to feed two or more electric machines in parallel and provide control laws to improve energy efficiency. This system is called a multimachine singleconverter system [17]. Thus, in high-power applications such as traction systems, two or more machines are fed by one converter. The control of multimachine single-converter systems is the subject of this study. Several methods have been proposed to control bimachine monoinverter systems. In this case, a master-slave based on nonlinear model predictive direct torque control (NMP-DTC) strategy is developed.

The motivation of the present work is to verify the enhancement of performances and stability of the electric vehicle, using a new multimachine robust control. This work realizes the acceleration slip regulation (ASR) and antilock braking system (ABS) functions, based on nonlinear model predictive (NMP) direct torque control (DTC) for four permanent magnet synchronous (PMS) in-wheel motors. The coordinated ASR and ABS control offers the wheel slip control through PMS in-wheel electric motors actuation both in traction and in braking mode.

This paper is organized as follows. In Section 2, the structure of the electric vehicle studied is presented. It is composed of two sets of bi-PMS in-wheel motors connected in parallel and supplied by a three-phase two-level inverter, one on the left and one on the right. In Section 3, a general description about the nonlinear model predictive direct torque control (NMP-DTC) for PMS in-wheel motor will be presented. A fuzzy logic control for the cost function optimization is studied and explained in detail. Section 4 discusses the principle of the new multimachine robust control, based on NMP-DTC for two permanent magnet synchronous (PMS) in-wheel motors operating in parallel and supplied by a single three-phase two-level inverter. The master-slave based on NMP-DTC is verified via simulation. High performance with respect to speed tracking and torque control of both motors has been demonstrated. In Section 5, the vehicle longitudinal dynamics and the fuzzy logic control strategy of ASR and ABS based on the wheel angular acceleration and the slip ratio are presented. Finally, the conclusion will be pointed out at the end of the paper.

\section{Structure of the Electric Vehicle Studied}

In this paper, the EV studied is equipped with four in-wheel motors (i.e., PMSMs) mounted in each wheel. The configuration of the vehicle system is shown in Figure 1. Two structures of the four-wheel independent driving electric vehicle are presented. As shown in Figure 1(a), each PMS in-wheel motor is fed by its own individual inverter. However, in Figure 1(b), we can see two sets of bi-PMS in-wheel motors which will be connected in parallel and supplied by a single inverter, one on the left and one on the right. Consequently, in the latter figure, the number of power electronic components is clearly reduced, and the volume and size of the system also decrease. Some studies have been carried out concerning control problems of these systems in $[34,35]$. Our work will be on the second structure for the motivation of this structure; not only does it allow the achievement of an electric differential system $[23,36]$, but also it opens opportunities for new ABS and ASR architectures. Furthermore, the individually controlled electric motors allow (i) reduction or even elimination of the involvement of conventional friction brakes into the control on the wheel slip and recuperation of the braking energy (in the case of ABS) and (ii) improvement of driving comfort. Within this context, the possible advantages of this structure are the faster response time and possibility of dual direct control, either by speed or by torque.

\subsection{Parallel Structure Studied. As shown in Figure 2, a three-} leg inverter will operate two machines simultaneously where each leg of the inverter is shared by all the machines. Therefore, the dimension of the power electronic components of the inverter must be in accordance with the number of machines in parallel. Besides, these machines must be as similar as possible in terms of electrical parameters. According to this structure, all the machines will exactly receive the same voltages in both frequency and amplitude. The angular speeds of the machines are thus identical. In our 


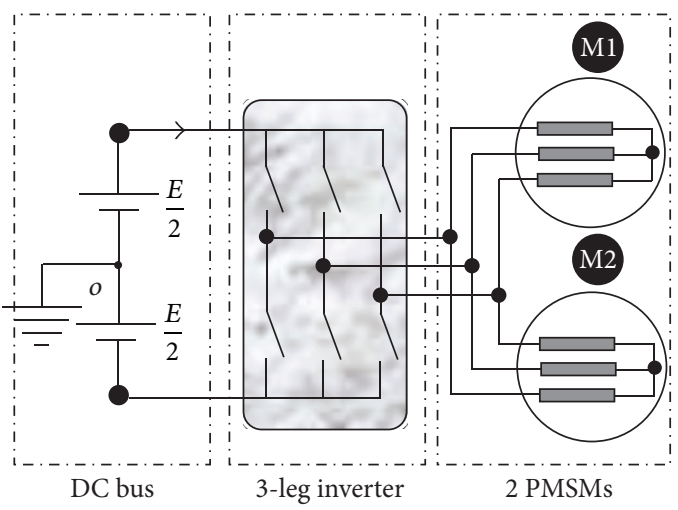

Figure 2: Parallel structure studied, bimachine monoinverter system.

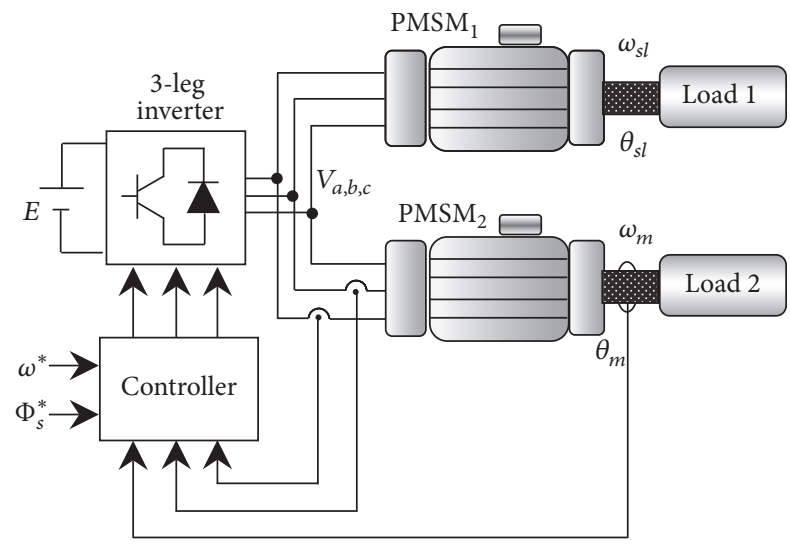

Figure 3: Parallel structure under master-slave configuration.

studied case, the set of bi-PMS in-wheel motors connected in parallel by the same inverter is on the left and on the right.

2.2. Master-Slave Control for Bimachine Monoinverter System. The classical approach is based on a master-slave structure, where the master machine will be piloted while the second is simply connected in parallel (Figure 3). For the master machine, it is then possible to determine the best control configuration of the inverter in order to minimize a criterion related to the current error.

The master-slave structure to operate the system has been used in [21]. The rotor position of the two motors is always compared. The motor with the higher load is set as the master, and the other one is assigned as the slave and is fed by the same voltage as the master.

Figure 4 shows the description of the master-slave configuration. A "master choice" block is added to the system in order to select the master machine. Therefore, only the master machine is controlled instantaneously, whereas the slave machine will operate in an open loop under the voltage supplying mode. As shown in Figure 4, the position and currents of the two machines are continuously recorded. A logic signal "Enable" allows choosing the master machine in order to carry out the speed and current control. This signal is created by calculating the difference $\left(\theta_{1}-\theta_{2}\right)$ and passing

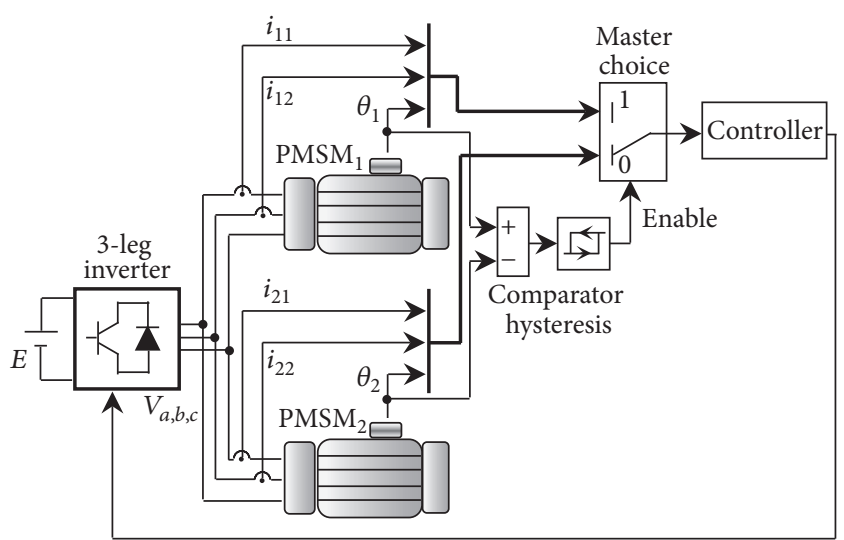

Figure 4: Master choice block.

this difference through a hysteresis comparator. If we have "Enable = 1," the master machine is PMSM1, and PMSM2 is the slave. On the contrary, if we have "Enable $=0$," PMSM2 is the master, and PMSM1 is the slave.

The problem of choosing the adequate machine to set as the master while respecting the stability condition of the complete system needs to be considered.

\section{Nonlinear Model Predictive Direct Torque Control for PMS In-Wheel Motors with Optimized Cost Function}

3.1. Mathematical Model of PMSM. A nonlinear model predictive control (NMPC) strategy is designed by first considering the electric vehicle system dynamics. The dynamic model of the PMSM drive in the $(d, q)$ rotor rotating reference frame is a nonlinear affine form as follows:

$$
\dot{x}(t)=A x(t)+B u(t)+B_{d} \Lambda_{d}(t),
$$

where

$$
\begin{aligned}
A & =\left[\begin{array}{cc}
-\frac{R_{s}}{L_{d}} & \frac{L_{q}}{L_{d}} \omega \\
-\frac{L_{q}}{L_{d}} \omega & -\frac{R_{s}}{L_{q}}
\end{array}\right], \\
B & =\left[\begin{array}{cc}
\frac{1}{L_{d}} & 0 \\
0 & \frac{1}{L_{q}}
\end{array}\right], \\
B_{d} & =\left[\begin{array}{l}
0 \\
1
\end{array}\right],
\end{aligned}
$$

and $x=\left[\begin{array}{ll}i_{d} & i_{q}\end{array}\right]^{T}$ and $u=\left[\begin{array}{ll}u_{d} & u_{q}\end{array}\right]^{T}$ represent the state variable vector and control input vector in continuous time, respectively, while $\Lambda_{d}=-\left(\Phi_{f} / L_{d}\right) \omega$.

Now, it follows that an MPC strategy intuits the decisionmaking of the human being in a discrete form, implying that the continuous-time model (1) should be transformed into a discrete-time model. 
Using the first-order Euler's approximation method, the predicted states in the discrete-time state space for an instant $k+1$ are given by

$$
x_{m}(k+1)=A_{m} x_{m}(k)+B_{m} u_{m}(k)+B_{d m} \Lambda_{d m}(k),
$$

where

$$
\begin{aligned}
& A_{m}=\left[\begin{array}{cc}
1-\frac{R_{s}}{L_{d}} T_{s} & \frac{L_{q}}{L_{d}} \omega T_{s} \\
-\frac{L_{q}}{L_{d}} \omega T_{s} & 1-\frac{R_{s}}{L_{q}} T_{s}
\end{array}\right], \\
& B_{m}=\left[\begin{array}{cc}
\frac{1}{L_{d}} T_{s} & 0 \\
0 & \frac{1}{L_{q}} T_{s}
\end{array}\right], \\
& B_{d m}=\left[\begin{array}{c}
0 \\
T_{s}
\end{array}\right] .
\end{aligned}
$$

And $x_{m}(k)$ and $x_{m}(k+1)$ are the state variable vectors in discrete time at the current sampling time $k$ and the next sampling time $k+1$, respectively, whereas $u_{m}(k)$ and $u_{m}(k-1)$ are the control input vectors at the current sampling time $k$ and the previous sampling time $k-1$, respectively, which can be written as

$$
u_{m}(k)=u_{m}(k-1)+\Delta u_{m}(k) .
$$

The $d-q$ stator currents $i_{d}(k+1)$ and $i_{q}(k+1)$ are generated from (3), while the $d-q$ current vectors $i_{d}(k)$ and $i_{q}(k)$ are determined from the measured stator current $i_{a b c}(k)$ using Park's transformation.

3.2. The Proposed NMP-DTC Technique. Figure 5 illustrates the block diagram of the proposed NMP-DTC system for PMS in-wheel motor. The speed controller used in this technique is an IP with antiwindup strategy, which was presented in [22]. Now, (3) allows the prediction of $d-q$ stator currents components which are used to predict the electromagnetic torque and stator flux linkage. Also, they determine the approximate switching states applied to the three-phase inverter.

The rotor position angle, $\theta(k)$, can be obtained by using an encoder and the rotor speed can be calculated using Euler's approximation method over a sampling time $T_{s}$ as follows:

$$
\omega(k)=\frac{\theta(k)-\theta(k-1)}{T_{s}} .
$$

The stator flux linkage can be constructed based on the predicted $d-q$ stator current components (3) as follows:

$$
\begin{aligned}
& \Phi_{d}(k+1)=L_{d} i_{d}(k+1)+\Phi_{f}, \\
& \Phi_{q}(k+1)=L_{q} i_{q}(k+1),
\end{aligned}
$$

where its magnitude

$$
\Phi_{s}(k+1)=\sqrt{\left[\Phi_{d}(k+1)\right]^{2}+\left[\Phi_{q}(k+1)\right]^{2}} .
$$

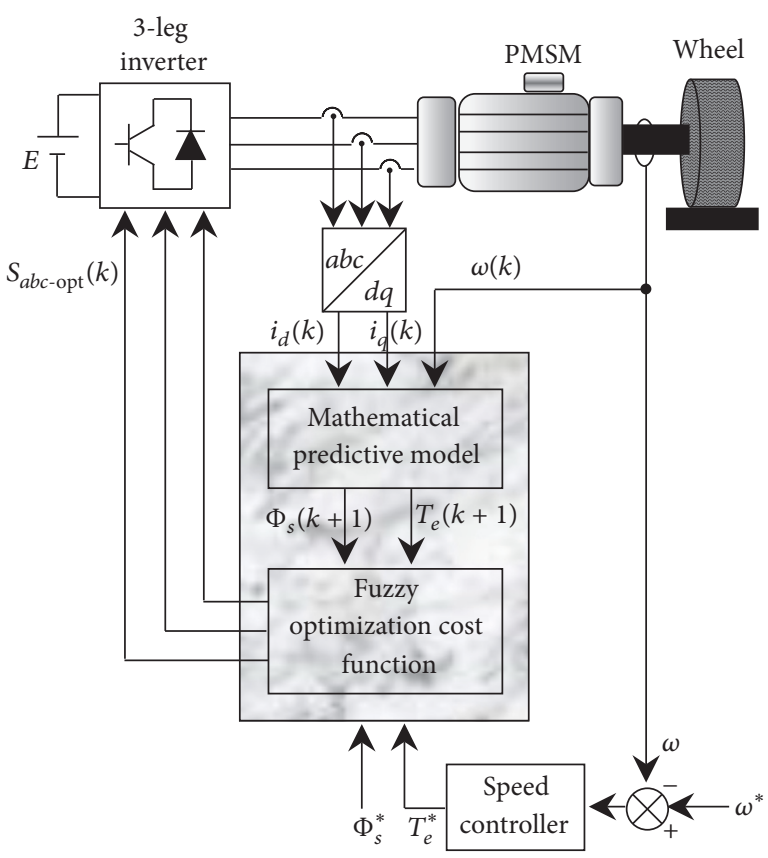

FIGURE 5: Block diagram of the proposed NMP-DTC technique.

Based again on the predictive $d-q$ stator currents at the instant $k+1$ in (3), the predicted electromagnetic torque is given by

$$
\begin{aligned}
& T_{e}(k+1) \\
& =\frac{3 p}{2}\left[\Phi_{f} i_{q}(k+1)+\left(L_{d}-L_{q}\right) i_{d}(k+1) i_{q}(k+1)\right] .
\end{aligned}
$$

Then, the control input vector $u_{m}=\left[\begin{array}{ll}u_{d m} & u_{q m}\end{array}\right]^{T}$ can be selected by the following:

$$
\begin{aligned}
& u_{m}(k) \\
& =\left[\begin{array}{cc}
\cos (\theta(k)) & -\sin (\theta(k)) \\
\cos \left(\theta(k)-\frac{2 \pi}{3}\right) & -\sin \left(\theta(k)-\frac{2 \pi}{3}\right) \\
\cos \left(\theta(k)+\frac{2 \pi}{3}\right) & -\sin \left(\theta(k)+\frac{2 \pi}{3}\right)
\end{array}\right]\left[\begin{array}{l}
S_{a}(k) \\
S_{b}(k) \\
S_{c}(k)
\end{array}\right],
\end{aligned}
$$

where $S_{a b c}(k)=\left[\begin{array}{lll}S_{a}(k) & S_{b}(k) & S_{c}(k)\end{array}\right]^{T}$ is the switching vector.

3.3. Fuzzy Cost Function Optimized. The predicted torque and stator flux linkage and their respective references are fed into the fuzzy cost function for error minimization (Figure 6). Note that, to evaluate the performance of the proposed NMPDTC, the torque $\Delta T_{e}=T_{e}^{*}-T_{e}(k+1)$ and stator flux $\Delta \Phi_{s}=\Phi_{s}^{*}-\Phi_{s}(k+1)$ errors must be minimized. Thus, the cost function $g_{i}\left(T_{e}, \Phi_{s}\right)$ which minimizes the $\Delta T_{e}$ and $\Delta \Phi_{s}$ errors is given as

$$
\begin{aligned}
g_{i}= & \left(\left|T_{e}^{*}-T_{e}(k+1)\right|\right)^{2}+\delta_{\Phi_{n}}\left(\left|\Phi_{s}^{*}-\Phi_{s}(k+1)\right|\right)^{2} \\
& +C_{\lim }\left\{i_{s}(k+1)\right\},
\end{aligned}
$$




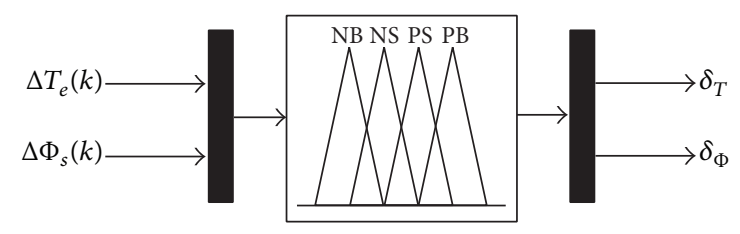

FIGURE 6: Fuzzy logic NMP-DTC technique.

where $\delta_{\Phi_{n}}$ represents the fixed weighting factor which is computed as

$$
\delta_{\Phi_{n}}=\frac{T_{n e}}{\Phi_{n s}},
$$

where $T_{n e}$ and $\Phi_{n s}$ correspond to the nominal magnitude of the electromagnetic torque and stator flux, respectively, in which $C_{\lim }\left\{i_{s}(k+1)\right\}$ is the nonlinear function which handles the limitations of the inverter and stator current.

Referring to (11), the fixed value of $\delta_{\Phi_{n}}$ can result in unsatisfactory performances, taking into account the dynamics of electric vehicle traction and linearities of a PMSM drive. Hence, the variable weighting factors $\delta_{T}$ and $\delta_{\Phi}$ are introduced in this paper, whereby their values are determined online by the FLC strategy in order to generate the optimal switching state $S_{a b c \text {-opt }}(k)$ at each sampling time $T_{s}$. Thus, the new cost function is established by the following:

$$
\begin{aligned}
\widetilde{g}_{i}= & \frac{\delta_{T}}{T_{n}^{2}}\left(\left|T_{e}^{*}-T_{e}(k+1)\right|\right)^{2} \\
& +\frac{\delta_{\Phi}}{\Phi_{s n}^{2}}\left(\left|\Phi_{s}^{*}-\Phi_{s}(k+1)\right|\right)^{2}+C_{\lim }\left\{i_{s}(k+1)\right\} .
\end{aligned}
$$

Thus, to guarantee the generation of the optimal switching state $S_{a b c-o p t}(k)$ minimizing the new cost function (13), the torque error and flux stator error should be accurately penalized at every sampling time index, $k$. Thus the following fuzzy rules for the two errors $\Delta T_{e}$ and $\Delta \Phi_{s}$ are applied to determine the weighting factors $\delta_{T}$ and $\delta_{\Phi}$, respectively.

Figure 6 indicates the fuzzy method to construct the two weighting factors $\left(\delta_{T}, \delta_{\Phi}\right)$ from $\Delta T_{e}$ and $\Delta \Phi_{s}$. In this case, the fuzzy rule sets that generate the weighting factors $\delta_{T}$ and $\delta_{\Phi}$ are given by the following:

IF $\Delta T_{e}$ is positive big (PB), THEN $\delta_{T}$ is PB.

IF $\Delta T_{e}$ is positive small (PS), THEN $\delta_{T}$ is PS.

IF $\Delta T_{e}$ is negative small (NS), THEN $\delta_{T}$ is NS.

IF $\Delta T_{e}$ is negative big (NB), THEN $\delta_{T}$ is NB.

Similar fuzzy rule sets can be applied to generate the weighting factor $\delta_{\Phi}$ for $\Delta \Phi_{s}$.

An algorithm of the proposed NMP-DTC strategy is shown in Figure 7.

Actually, the electromagnetic torque $T_{e}(k+1)$ and stator flux linkage $\Phi_{s}(k+1)$ are depicted using a mathematical predictive model. Note that, for each sampling time $T_{s}$, the optimal switching signals $S_{a b c-o p t}(k)$ are determined by minimizing the cost function (13) and using the dynamic weighting factors $\left(\delta_{T}, \delta_{\Phi}\right)$ which are tuned by the FLC technique.

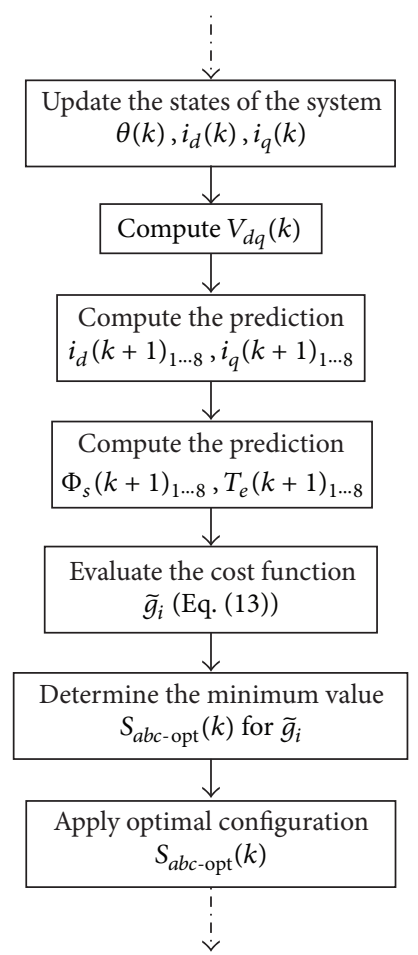

FIGURE 7: Flowchart of the NMP-DTC algorithm.

\section{New Master-Slave NMP-DTC with Load Torque Observer}

4.1. Principle of the Proposed Method. The proposed method is based on the nonlinear model predictive direct torque control (NMP-DTC) algorithm for controlling a system composed of two permanent magnet synchronous motors (PMSMs) operating in parallel, fed by a single power inverter, which is the case of longitudinal half of the electric vehicle (EV) studied, on the right side or the left side, as seen in Figure 14. Thus, the two predictive motors' torque and stator flux vectors for each motor are evaluated by a new cost function that will be found to get the optimum voltage vector, which minimizes the motor torque and stator flux errors. Therefore, the new cost function chosen for this system will be built as follows:

$$
\begin{aligned}
& g_{i} \\
& =\frac{\delta_{T}}{T_{n}^{2}}\left\{\left(\left|T_{e 1}^{*}-T_{e 1}(k+1)\right|\right)^{2}+\left(\left|T_{e 2}^{*}-T_{e 2}(k+1)\right|\right)^{2}\right\} \\
& \quad+\frac{\delta_{\Phi}}{\Phi_{s n}^{2}}\left(\left|\Phi_{s m}^{*}-\Phi_{s m}(k+1)\right|\right)^{2}+C_{\lim }\left\{i_{s}(k+1)\right\} .
\end{aligned}
$$

In this system, it is expected that both motors will get the same speed even if they have different conditions of load torque. For stable parallel operation of PMS motors with a single inverter, each motor has to be constantly kept in the synchronization state regardless of load torque. If the master motor with the larger load is controlled, the synchronous state 


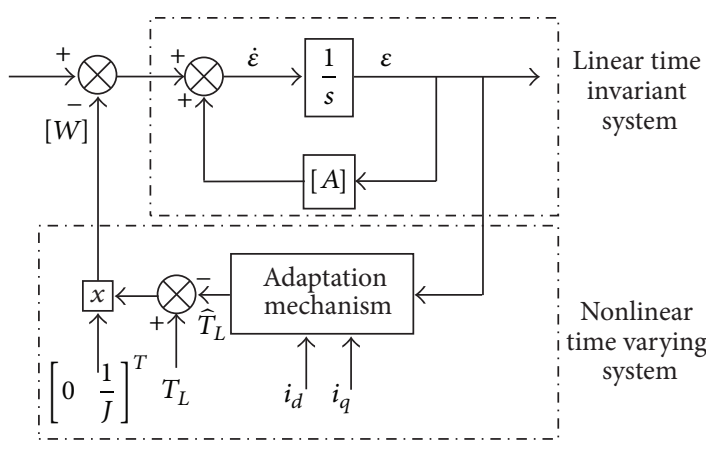

FIGURE 8: Block diagram of the proposed load torque observer.

will be maintained. Therefore, detection of the master motor is essential.

Next, the design for the complete operation of the proposed master-slave NMP-DTC strategy can be summarized below.

Step 1. At $k$ instant time, measure the stator currents $\left(i_{a b c 1}(k), i_{a b c 2}(k)\right)$ and rotor positions $\left(\theta_{1}(k), \theta_{2}(k)\right)$, and then determine $\left(i_{d q 1}(k), i_{d q 2}(k)\right)$ and $\left(\omega_{1}(k), \omega_{2}(k)\right)$.

Step 2. Obtain the prediction control $\left(i_{d q 1}(k+1), i_{d q 2}(k+1)\right)$, the prediction $\left(T_{e 1}(k+1), T_{e 2}(k+1)\right)$, and $\left(\Phi_{s 1}(k+1), \Phi_{s 2}(k+\right.$ 1)) for all the possible $S_{a b c}(k)$.

Step 3. Generate the reference of the stator flux of the master motor $\Phi_{s m}^{*}(k+1)$ selected by master-slave switching.

Step 4. Evaluate the cost function (14) with dynamic weighting factors $\left(\delta_{T}, \delta_{\Phi}\right)$ tuned by the FLC technique.

Step 5. Determine the optimal switching state, $S_{a b c \text {-opt }}(k)$ for driving the three-phase inverter.

Step 6. Set $k+1$. Go to Step 1 .

4.2. Load Torque Observation Based on MRAS. As described in the previous section, the choice of the master motor requires knowledge of the load torque values of the two PMS motors. In this paper, an estimation method is proposed to identify online these load torques, based on model reference adaptive system (MRAS) through Popov's hyperstability criteria (Figure 8 ).

The motion model of PMSM in rotor reference frame, neglecting viscosity coefficient and supposing the $d$-axis current to be zero, is given as follows:

$$
[\dot{X}]=[A][X]+[B][U]+[D]
$$

where

$$
[A]=\left[\begin{array}{cc}
-\frac{R_{s}}{L_{s}} & \frac{L_{q}}{L_{d}} \omega \\
-\frac{L_{q}}{L_{d}} \omega & -\frac{R_{s}}{L_{s}}
\end{array}\right],
$$

$$
\begin{gathered}
B=\left[\begin{array}{c}
\frac{1}{L_{s}} \\
0
\end{array}\right], \\
{[U]=V_{q},} \\
{[D]=\left[\begin{array}{c}
0 \\
\frac{T_{L}}{J}
\end{array}\right] .}
\end{gathered}
$$

Using the estimations of $\widehat{T}_{L}$, the adjustable model is constructed:

$$
[\dot{X}]=[A][\widehat{X}]+[B][U]+[\widehat{D}]
$$

One makes the subtraction between the two models (15) and (17):

$$
[\dot{\varepsilon}]=[A][\varepsilon]-[W],
$$

where

$$
\begin{aligned}
{[\varepsilon] } & =[X]-[\widehat{X}]=\left[\begin{array}{l}
\varepsilon_{d} \\
\varepsilon_{q}
\end{array}\right], \\
{[W] } & =-\Delta[D], \\
\Delta[D] & =\left[\begin{array}{l}
0 \\
\frac{1}{J}
\end{array}\right]\left(T_{L}-\widehat{T}_{L}\right) .
\end{aligned}
$$

According to Popov's stability,

$$
\int_{0}^{t_{0}}[E]^{T}[W] d t=t \geq-\gamma_{0}^{2}
$$

Inequality (20) can be divided into two components as follows:

$$
\widehat{T}_{L}=A_{5}([\varepsilon])+\int_{0}^{t_{0}} A_{6}([\varepsilon]) d t .
$$

When using the expression of $W$, inequality (20) becomes

$$
\int_{0}^{t_{0}}\left\{\left[\varepsilon_{q} \frac{1}{J_{m}}\right]\right\}\left[\left(T_{L}-\widehat{T}_{L}\right)\right] d t \geq-\gamma_{0}^{2} .
$$

Using $\widehat{T}_{L}$, the criterion of Popov for the current system becomes

$$
\begin{aligned}
\int_{0}^{t_{0}}\{ & {\left.\left[\varepsilon_{q} \frac{1}{J_{m}}\right]\right\} } \\
& \times \int_{0}^{t_{0}}\left\{T_{L}-A_{4}([\varepsilon])-\int_{0}^{t_{0}} A_{5}([\varepsilon]) d t\right\} d t \\
\geq & -\gamma_{0}^{2} .
\end{aligned}
$$


A solution of this inequality can be found in relationship [37]. Then, the load torque observed satisfies the following adaptation laws:

$$
\begin{aligned}
& A_{5}=k_{5}\left[\varepsilon_{q} \frac{1}{J_{m}}\right], \\
& A_{6}=k_{6}\left[\varepsilon_{q} \frac{1}{J_{m}}\right],
\end{aligned}
$$

where $k_{5}$ and $k_{6}$ are the positive adaptation gains. Substituting $A_{5}$ and $A_{6}$ in (21), it can be easily shown that the observed load torque satisfies the following adaptation law:

$$
\widehat{T}_{L}=A_{5}([\varepsilon])+\frac{1}{p} A_{6}([\varepsilon]) .
$$

The estimated load torque is generated from the adaptive mechanism using the error between the estimated currents and references obtained by the model as follows:

$$
\widehat{T}_{L}=k_{p}\left[\varepsilon_{q} \frac{1}{J_{m}}\right]+k_{i} \int_{0}^{t}\left[\varepsilon_{q} \frac{1}{J_{m}}\right] d t+\widehat{T}_{L}(0),
$$

where $k_{p}$ and $k_{i}$ are two parameters of the PI controller and $\widehat{T}_{L}(0)$ is the initial estimated load torque.

\subsection{Tracking Performance under Variable Load Torque. In} order to ensure the stability of the system composed of two PMS machines connected in parallel on the same inverter, controlled by the master-slave NMP-DTC strategy, different loads are applied to both machines. The varieties of the load of two PMS machines are represented in Figure 9(a).

Figure 9 shows the responses of the two PMS machines which will be controlled at three set points of speed under different load conditions. It is shown that the synchronism of these machines is guaranteed. Besides, the system has proved its stability towards the sudden changes of the load of the two machines. Their speeds are approximately the same and follow the reference, and the speeds tracking performance is satisfactorily achieved, as seen in Figure 9(b). Figure 9(c) shows the zoomed-in region (around 0,4 and 0,8 seconds) of Figure 9(b). At the transient state by load fluctuation, M1 speed vibrates around M2 speed and both machines become stable at the reference speed. Likewise, Figure 9(d) shows the zoomed-in region (around 1,4 and 1,8 seconds) of Figure 9(b), which has the same behavior. We can also notice that there is no ripple speed at standstill.

We notice in Figure 9(e) that the fast response of the electromagnetic torques of the two machines, master and slave, confirms the speed and good alternation in master and slave, under load conditions. In addition, the torque ripple is quite small, approximately $0,5 \mathrm{~N} \cdot \mathrm{m}$, compared with the conventional DTC found in [17].

Figure 9(f) shows a good magnetic stability of both machines. In Figure 9(g), the currents of phase (a) of the two machines present good waveforms and confirm the responses of the machines regarding the load variations, which can be seen in Figures 9(h) and 9(i).
From this simulation, we can conclude that the "masterslave" structure with NMP-DTC is an interesting and powerful solution for the management of the two PMSMs in parallel on the same inverter, on the left side or the right side of the electric vehicle studied.

\section{Longitudinal Control of 4WID Electric Vehicle Based on the New Master-Slave NMP-DTC Technique}

5.1. Longitudinal Vehicle Dynamics. As shown in Figure 10, the longitudinal vehicle dynamics are analyzed based on a quarter-vehicle model as described by the following equations:

$$
\begin{aligned}
M_{v} \dot{v}_{x} & =F_{d}-F_{\text {res }}, \\
J_{\omega} \dot{\omega}_{i} & =T_{m i}-R_{\omega} F_{\text {res }}-c_{r r} F_{z}, \\
F_{d} & =\mu_{i}(\lambda) F_{z i} .
\end{aligned}
$$

The normal load expression for each wheel could be written as

$$
\begin{gathered}
F_{z(f l, f r)}=\left(\frac{M_{v} g}{2} \pm M_{v} a_{y} \frac{h}{d_{f}}\right) \frac{l_{r}}{l}-\frac{M_{v} h}{2 l} a_{x}, \\
F_{z(r l, r r)}=\left(\frac{M_{v} g}{2} \pm M_{v} a_{y} \frac{h}{d_{r}}\right) \frac{l_{r}}{l}+\frac{M_{v} h}{2 l} a_{x}
\end{gathered}
$$

where $i$ is $(f l, f r, r l, r r), M_{v}$ is the vehicle mass, $F_{d}$ is the driving force, $F_{\text {res }}$ is the driving resistance, $J_{\omega}$ is the wheel inertia, $\omega_{i}$ is the wheel rotational speed, $T_{m i}$ is the driving torque of the in-wheel motor, and $c_{r r}, \mu_{i}$, and $F_{z i}$ are the coefficient of rolling friction, friction coefficient of the $i$ th wheel, and the normal force of $i$ th tire, respectively.

5.2. Tire Model. Pacejka [38] presented the Magic Formula tire model and gave a clear physical meaning of the model parameters. Due to its high accuracy, the Magic Formula model has been used widely to simulate the tire/road friction $[39,40]$. The Magic Formula tire model described the longitudinal friction coefficient $\mu$ variation with the slip ratio $\lambda$ as follows:

$$
\mu=D \sin \{a \tan [B \lambda(1-E)+a \tan (B \lambda)]\},
$$

where the coefficients $B, C, D$, and $E$ depend on the wheel load $F_{z}$ and the slip ratio $\lambda$.

The relationship between the longitudinal friction coefficient and the slip ratio under different road conditions is shown in Figure 11.

5.3. ASR/ABS Control Design. In slippery road conditions, a large driving/braking torque easily causes a rapid increase of the slip ratio and thus entrance into the unstable region. The sudden loss of traction (i.e., smaller $\mu$ ) may lead to vehicle skidding [17].

(i) Angular Acceleration. Now, we will define angular acceleration $\left(\dot{\omega}_{a}, \dot{\omega}_{f}\right)$ of both acceleration/braking modes. Ignoring 

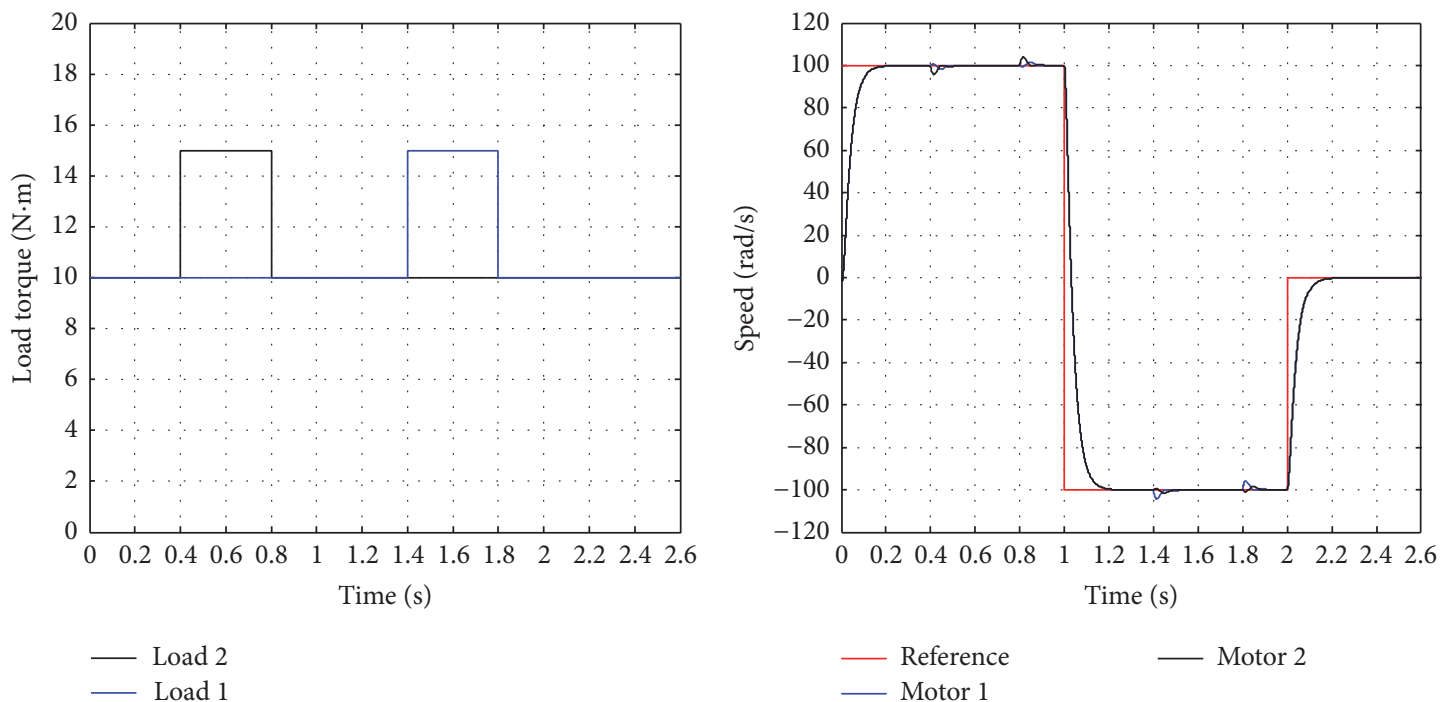

(a)

(b)
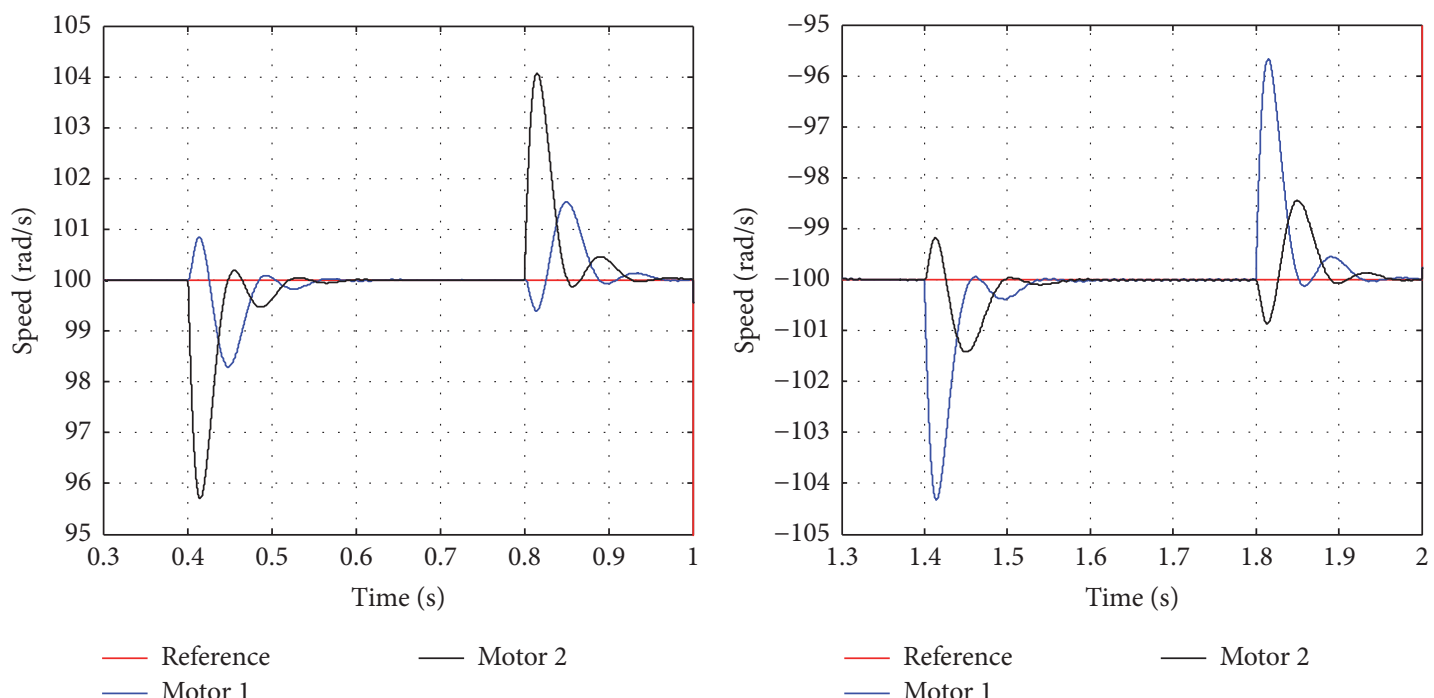

(c)

(d)
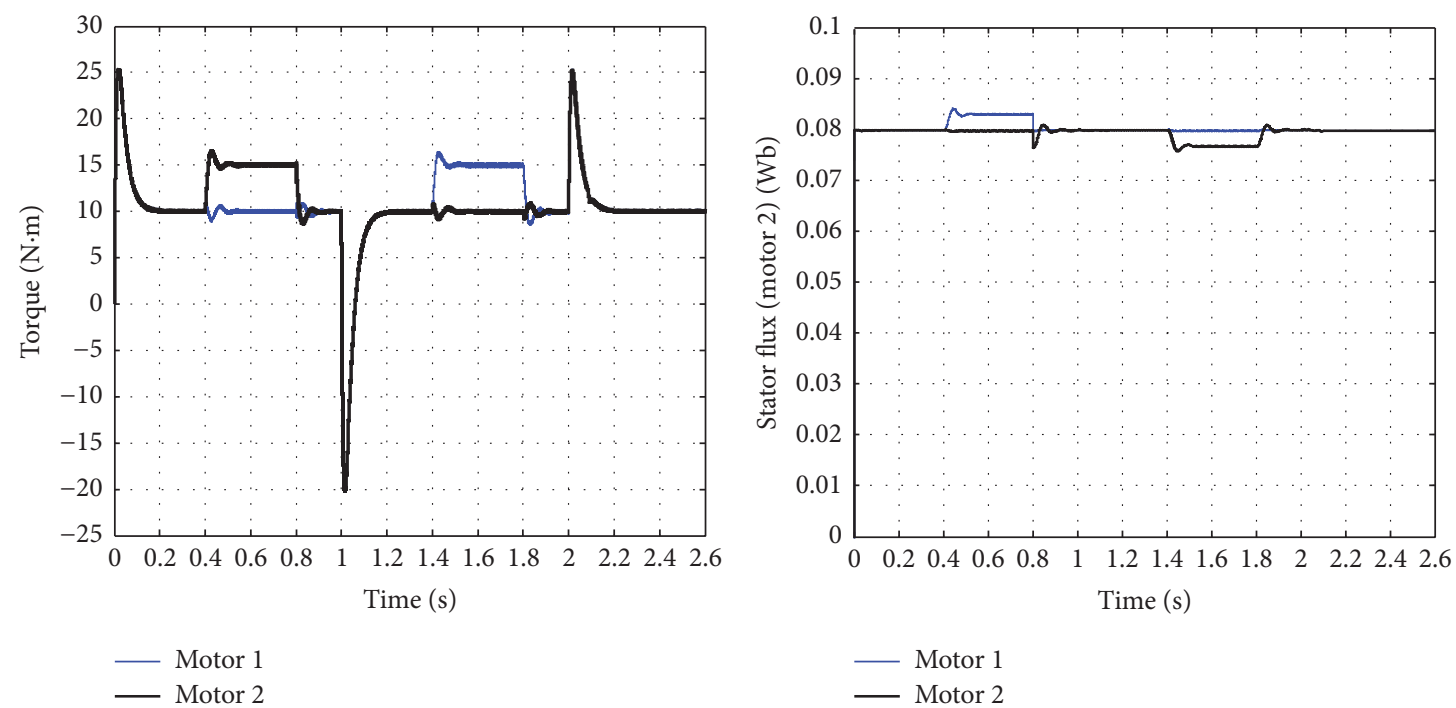

(e)

(f)

Figure 9: Continued. 

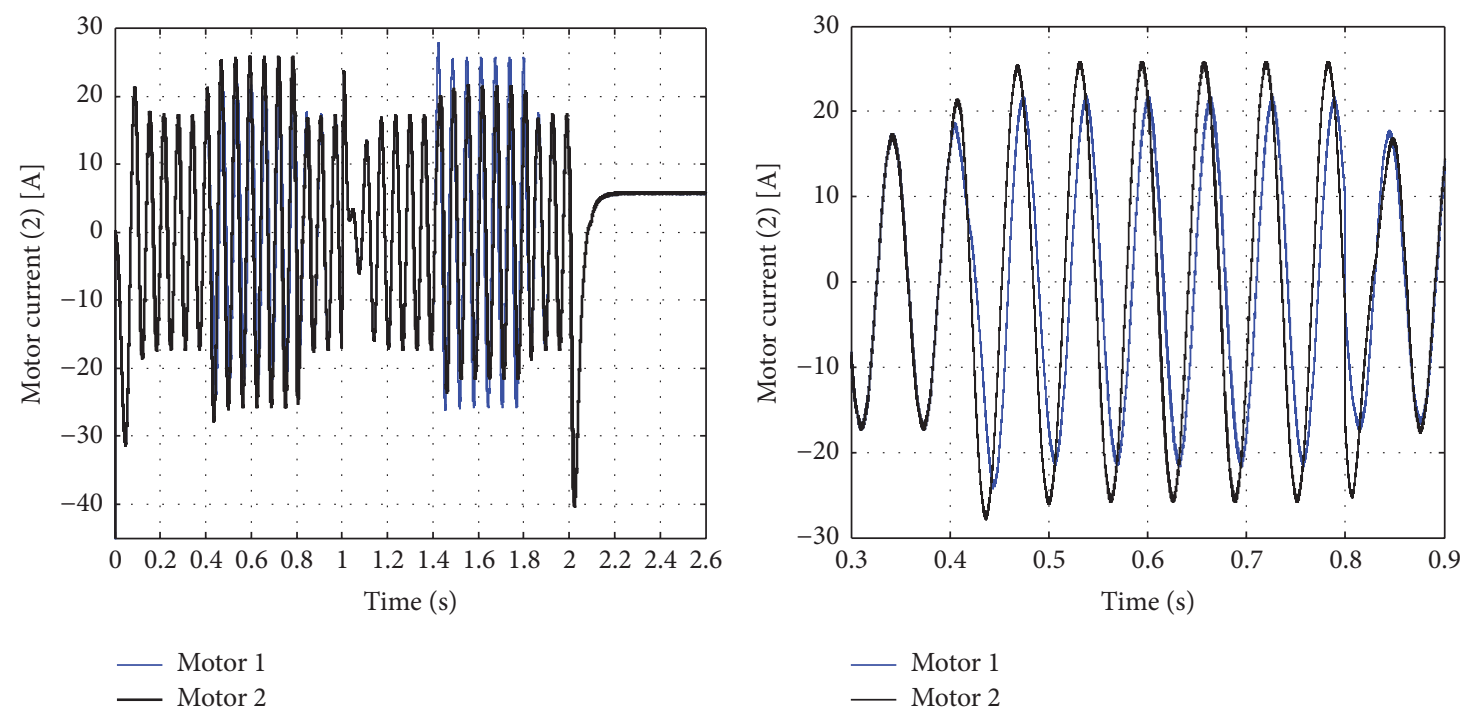

(g)

(h)

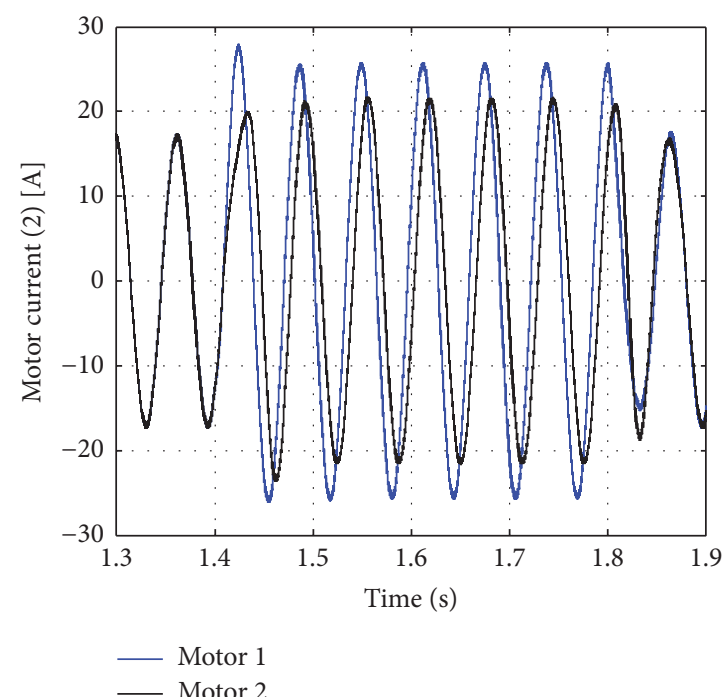

(i)

Figure 9: Simulation results under variable load torque.

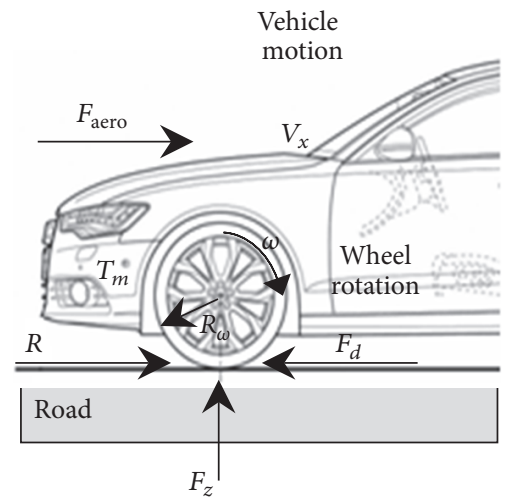

FIGURE 10: The quarter-vehicle model. 


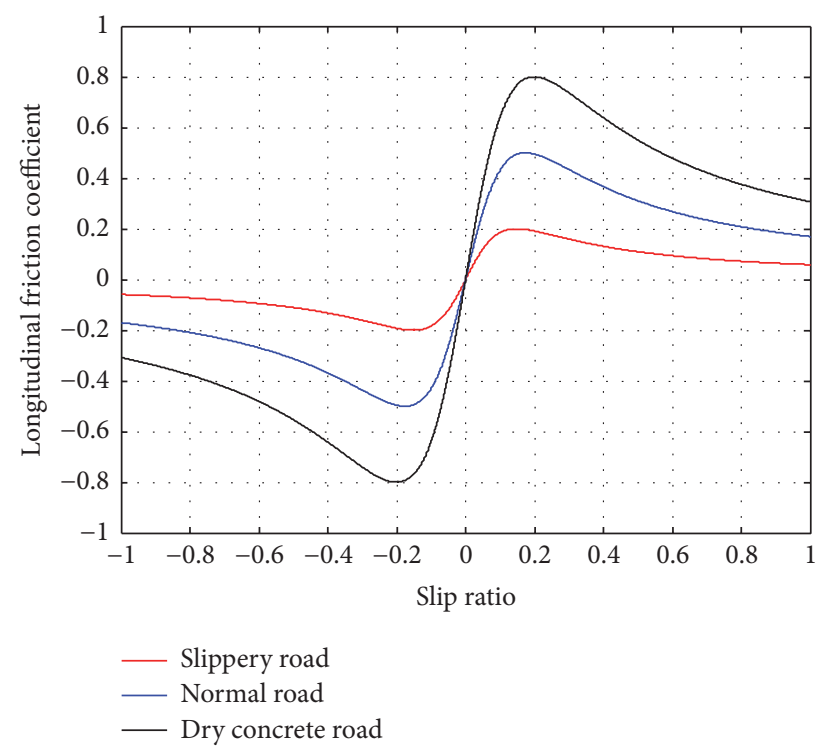

FIGURE 11: The relationship between the longitudinal friction coefficient and the slip ratio.

the rolling resistance and wind resistance, the relationship between the wheel angular acceleration $\dot{\omega}$, motor torque $T_{m}$, and slip ratio $\lambda$ can be described by the following formulas [41].

(ii) For Acceleration. One has

$$
\begin{aligned}
\dot{\lambda} & =\frac{-\dot{v}_{x} R_{\omega} \omega+\dot{\omega} R_{\omega} v_{x}}{\omega^{2} R_{\omega}^{2}} \\
& =\frac{\left[J_{\omega}+(1-\lambda) M_{v} R_{\omega}^{2}\right] \dot{\omega}-T_{m}}{\omega M_{v} R_{\omega}^{2}}, \\
\dot{\omega}_{a} & =\frac{T_{m}}{J_{\omega}+(1-\lambda) M_{v} R_{\omega}^{2}}+\frac{\omega M_{v} R_{\omega}^{2} \dot{\lambda}}{J_{\omega}+(1-\lambda) M_{v} R_{\omega}^{2}} .
\end{aligned}
$$

(iii) For Braking. One has

$$
\begin{aligned}
& \dot{\lambda}=\frac{-v_{x} R_{\omega} \dot{\omega}+\dot{\omega} R_{\omega} \dot{v}_{x}}{V_{x}^{2}} \\
& =\frac{\left((1+\lambda)^{2} / M_{v} R_{\omega}^{2}\right) T_{m}-\left[(1+\lambda)+(1+\lambda)^{2} / M_{v} R_{\omega}^{2}\right] \dot{\omega}}{\omega}, \\
& \dot{\omega}_{b}=\frac{(1+\lambda) T_{m}}{J_{\omega}(1+\lambda)+M_{v} R_{\omega}^{2}}+\frac{\omega \dot{\lambda}}{J_{\omega}(1-\lambda)+M_{v} R_{\omega}^{2}} .
\end{aligned}
$$

If the slip ratio $\lambda$ slowly increases $(\dot{\lambda}=0)$, then the wheel angular acceleration can be represented as follows:

$$
\begin{gathered}
\dot{\omega}_{a}=\frac{T_{m}}{J_{\omega}+(1-\lambda) M_{v} R_{\omega}^{2}}, \\
\dot{\omega}_{b}=\frac{(1+\lambda) T_{m}}{J_{\omega}(1+\lambda)+M_{v} R_{\omega}^{2}} .
\end{gathered}
$$

TABLE 1: Fuzzy logic rules.

\begin{tabular}{lccccccc}
\hline$T_{c}$ & \multicolumn{7}{c}{$\Delta_{1}=\dot{\omega}-\dot{\omega}_{p}$} \\
\hline$\Delta_{2}=\dot{\lambda}-\dot{\lambda}_{\text {opt }}$ & $\mathrm{NL}$ & $\mathrm{NM}$ & $\mathrm{NS}$ & $\mathrm{Z}$ & $\mathrm{PS}$ & $\mathrm{PM}$ & $\mathrm{PL}$ \\
$\mathrm{NS}$ & $\mathrm{Z}$ & $\mathrm{Z}$ & $\mathrm{Z}$ & $\mathrm{Z}$ & $\mathrm{Z}$ & $\mathrm{Z}$ & $\mathrm{Z}$ \\
$\mathrm{Z}$ & $\mathrm{Z}$ & $\mathrm{Z}$ & $\mathrm{Z}$ & $\mathrm{Z}$ & $\mathrm{Z}$ & $\mathrm{PS}$ & $\mathrm{PS}$ \\
$\mathrm{PS}$ & $\mathrm{Z}$ & $\mathrm{Z}$ & $\mathrm{Z}$ & $\mathrm{Z}$ & $\mathrm{PS}$ & $\mathrm{PM}$ & $\mathrm{PM}$ \\
$\mathrm{PM}$ & $\mathrm{Z}$ & $\mathrm{Z}$ & $\mathrm{PS}$ & $\mathrm{PS}$ & $\mathrm{PM}$ & $\mathrm{PL}$ & $\mathrm{PL}$ \\
$\mathrm{PL}$ & $\mathrm{Z}$ & PS & PM & PM & PL & PL & PL \\
\hline
\end{tabular}

(iv) Threshold Angular Acceleration. According to the automobile theory, when the wheel goes in the slip state during driving, wheel angular acceleration and slip ratio increase rapidly. Therefore, in order to ensure ASR performance and to obtain high driving force, the slip ratio should be near the optimal value. The angular acceleration threshold value can be described as follows:

$$
\begin{aligned}
& \dot{\omega}_{a p}=\frac{T_{m}}{J_{\omega}+\left(1-\lambda_{\mathrm{opt}}\right) M_{v} R_{\omega}^{2}}, \\
& \dot{\omega}_{b p}=\frac{\left(1+\lambda_{\mathrm{opt}}\right) T_{m}}{J_{\omega}\left(1+\lambda_{\mathrm{opt}}\right)+M_{v} R_{\omega}^{2}} .
\end{aligned}
$$

The tire/road friction coefficient varies with the tire slip ratio. And there is the optimal slip ratio at which the tire/road friction coefficient reaches the maximum which relates to the road conditions directly. Based on the experimental road, the vehicle will achieve a good acceleration performance when the slip ratio is between $(0.05: 0.2)$.

5.4. Fuzzy Logic ASR/ABS Controller. In this paper, a fuzzy ASR/ABS controller is designed according to the principle of fuzzy control to maintain the wheel slip within the optimal range by adjusting the motor torque dynamically. In the fuzzy logic controller, there are two input variables, $\Delta_{1}=\dot{\omega}-\dot{\omega}_{p}$, the difference between actual angular acceleration and threshold angular acceleration, and $\Delta_{2}=\dot{\lambda}-\dot{\lambda}_{\text {opt }}$, the difference between actual slip ratio and optimal slip ratio. The controller generates the compensation torque $T_{c}$ according to the input current fuzzy and the fuzzy rules. The basic rules of the fuzzy controller are summarized in Table 1.

The membership functions for the two input variables, $\Delta_{1}$ and $\Delta_{2}$, and the output variable $T_{c}$ are shown in Figure 12 .

If the actual angular acceleration is larger than the threshold angular acceleration, this indicates a dangerous situation that may lead to serious vehicle skid. In order to ensure the antiskid performance, a big increment of the compensation torque $T_{c}$ is needed to quickly decrease the motor torque $T_{m}$ to prevent vehicle skid as soon as possible. However, if the actual angular acceleration is less than the threshold angular acceleration, the driving wheel adhesion is in a good condition. This situation is not dangerous and the zero compensation torque can be applied.

In order to minimize the influence on the acceleration performance, the compensation torque $T_{c}$ is adjusted by using 


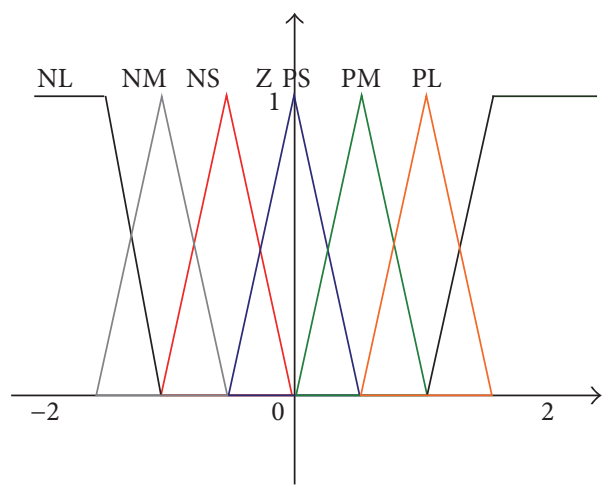

(a) $\Delta_{1}$

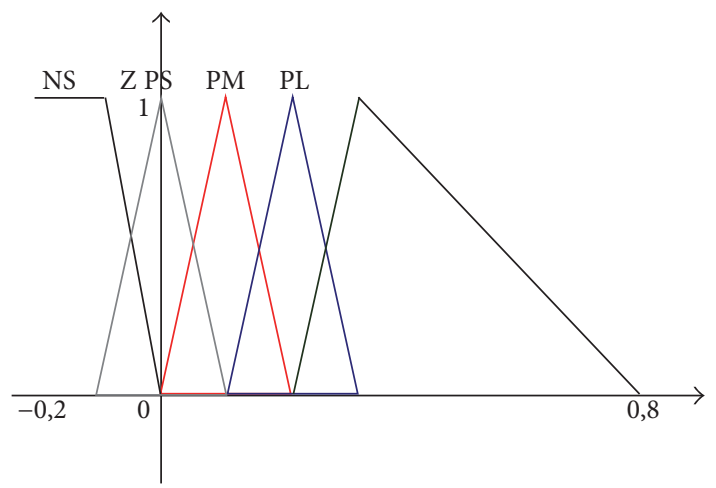

(b) $\Delta_{2}$

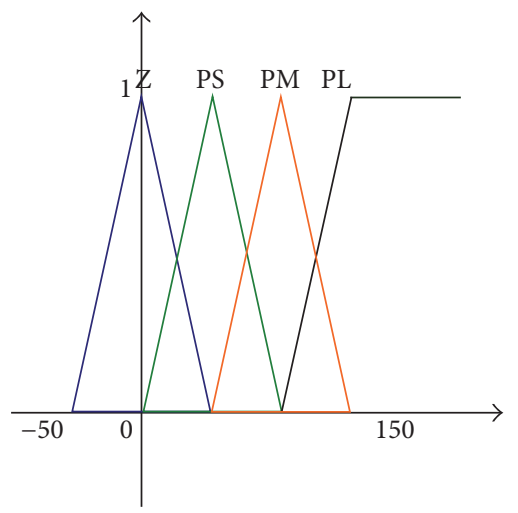

(c) $T_{c}$

FIGURE 12: Membership functions for fuzzy input and output variables.

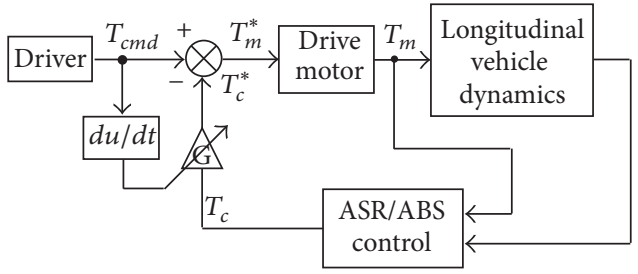

(a)

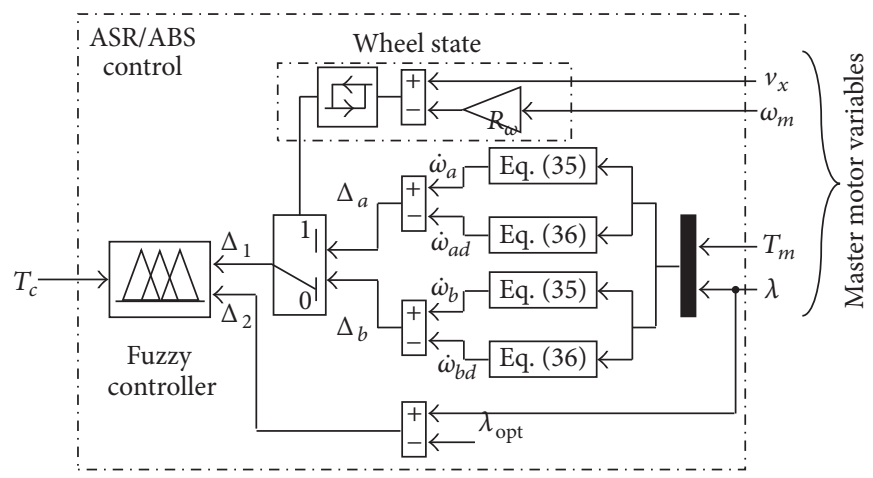

(b)

FIGURE 13: Block diagram of ASR/ABS control.

the increasing rate of $T_{c m d}$. This method is similar to the solution discussed in [3]. The compensation torque $T_{c}$ is multiplied by the variable coefficient $G$, which is defined as

$$
G=1-K \dot{T}_{c m d},
$$

where $\dot{T}_{c m d}$ is the increasing rate of $T_{c m d}$ and $K$ is a compensation gain. The upper and lower bounds of $G$ are one and zero, respectively.

As shown by the block diagram of ASR/ABS control in Figure 13(a), the electric vehicle generates driver's torque reference $T_{c m d}$ according to the driver's instructions. The proposed ASR/ABS controller properly regulates four torques of the motor and generates the compensation torque $T_{c}$ for vehicle skid prevention. The final motor torque command $T_{m}^{*}$ is the difference between $T_{c m d}$ and $T_{c}$.

According to the structure of the EV seen in Figure 1(b), the proposed combined ASR/ABS control, described in Figure 13(b), uses as inputs the torque motor $T_{m}$, angular speed $\omega_{m}$, actual angular acceleration $\dot{\omega}_{m}$, actual slip ratio $\lambda$, and vehicle speed $v_{x}$ of the master motor which is selected by the master-slave switching, presented in the previous section. 


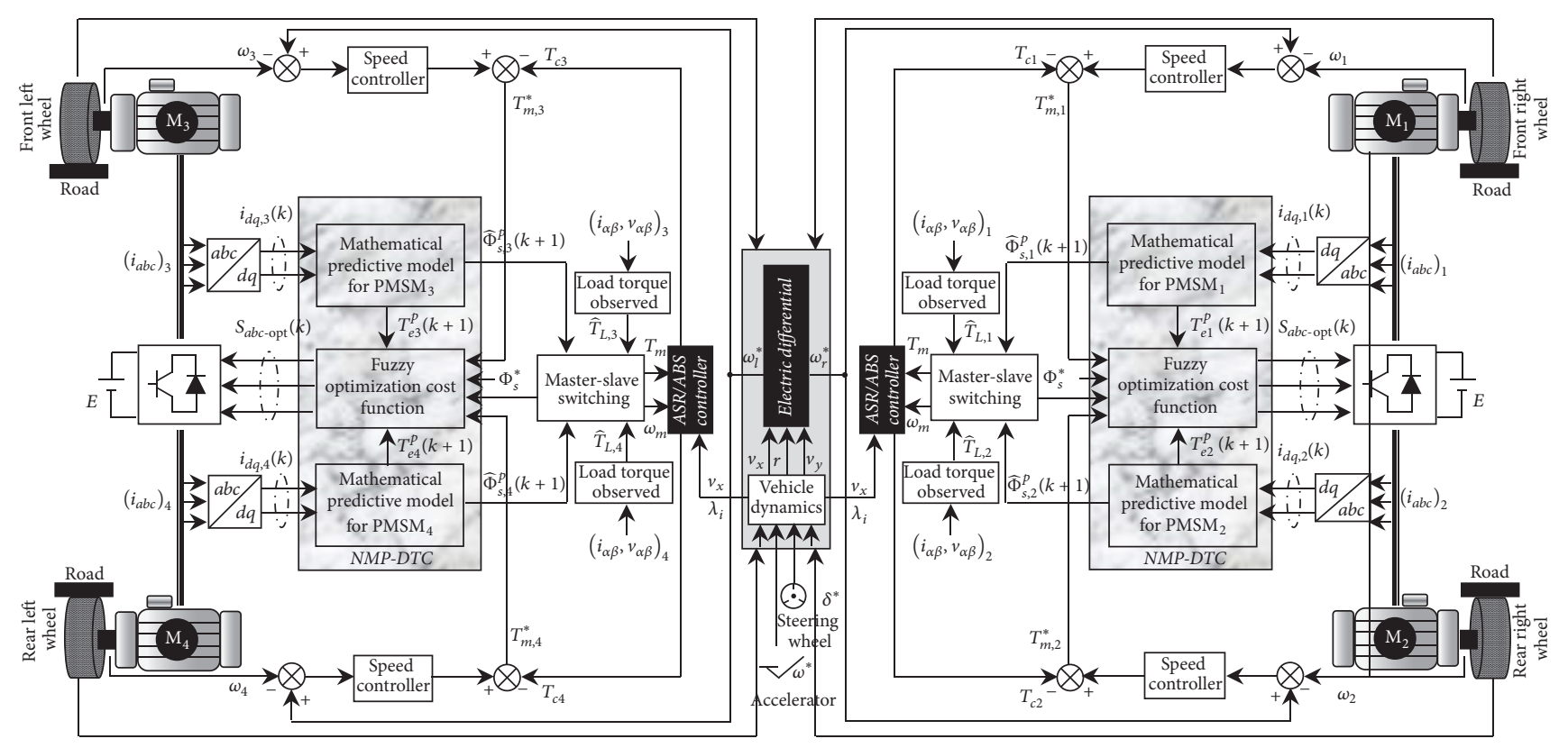

FIGURE 14: Block diagram of the longitudinal control of 4WID electric vehicle based on a new master-slave NMP-DTC technique.

Figure 14 shows the dynamical model of the considered electric vehicle with a four-in-wheel-motor topology that was numerically implemented on Matlab/Simulink. The proposed system uses the vehicle speed and the steering angle as input parameters. The block named "electric differential" provides the difference of speed for the four in-wheel motors and adapts the speeds of the left and right wheels differently, according to the steering angle. The common reference speed $\omega^{*}$ is then set by the accelerator pedal command. The actual reference speeds for the left drives $\left(\omega_{3}^{*}, \omega_{4}^{*}\right)$ and the right drives $\left(\omega_{1}^{*}, \omega_{2}^{*}\right)$ can then be obtained by adjusting the common reference speed $\omega^{*}$ and the steering angle.

\section{Simulation and Discussion}

In this section, a simulation model of vehicle dynamics is presented in order to evaluate the effectiveness of the proposed longitudinal control which combines the ASR and ABS functions for 4WID electric vehicles in acceleration and deceleration test maneuvers under various road conditions. The four in-wheel motors, with two inverters supplied by DC voltage source, are controlled by a new master-slave, based on nonlinear model predictive direct torque control. (1) and (2) in the Notations summarize the PMSMs and vehicle parameters, respectively.

In Acceleration Maneuver. The vehicle model will start accelerating at an initial velocity of $0 \mathrm{~m} / \mathrm{s}$ to $21 \mathrm{~m} / \mathrm{s}$. The first loss of adherence (the passage of the electric vehicle from a dry road to a slippery road) of the four wheels starts at 7 seconds and lasts 5 seconds in this acceleration mode (Figure 15). The simulation results are shown in Figure 16 which shows the velocities of the wheels and vehicle, slip ratios, actual and threshold angular acceleration of wheels, motor torques, traction forces, compensation and driver

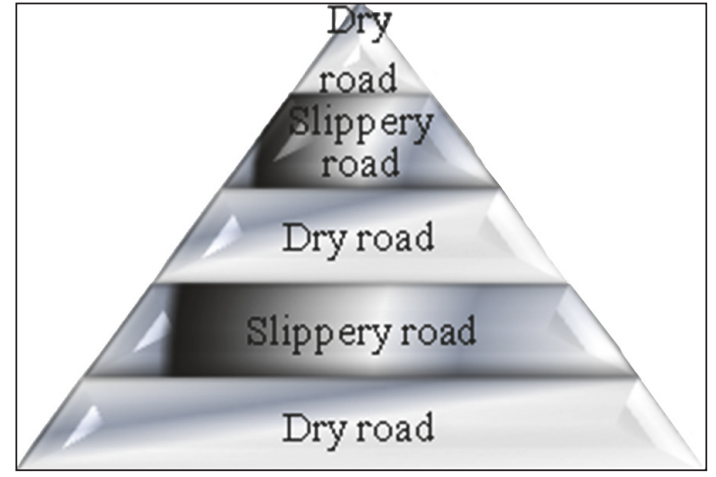

FIGURE 15: Test of the EV driven under different road conditions.

torques, and longitudinal, lateral, and angular velocities and acceleration.

In the conditions of acceleration process, when the vehicle enters a slippery road, the longitudinal slip of the four wheels increases rapidly to get a large driving force, and the real longitudinal slip of each wheel is kept within the optimal longitudinal slip of 0.05 . From Figure 16(b), we notice that the slip ratios of the wheels are maintained within the optimal range. Therefore, it is confirmed that the ASR control could maintain the slip ratios around their optimal values and improve the stability of the electric vehicle. It can be seen from Figure 16(b) that the actual slip ratios can track their optimal slip ratios on different road conditions. In addition, the acceleration slip regulation (ASR) has a great effect to maintain permanently the vehicle speed and the in-wheel motors' speed close to their profiles during the loss of adherence. Consequently, the proposed ASR controller generates the torque compensation for the wheels slip prevention to decrease the motor torques (see Figures 


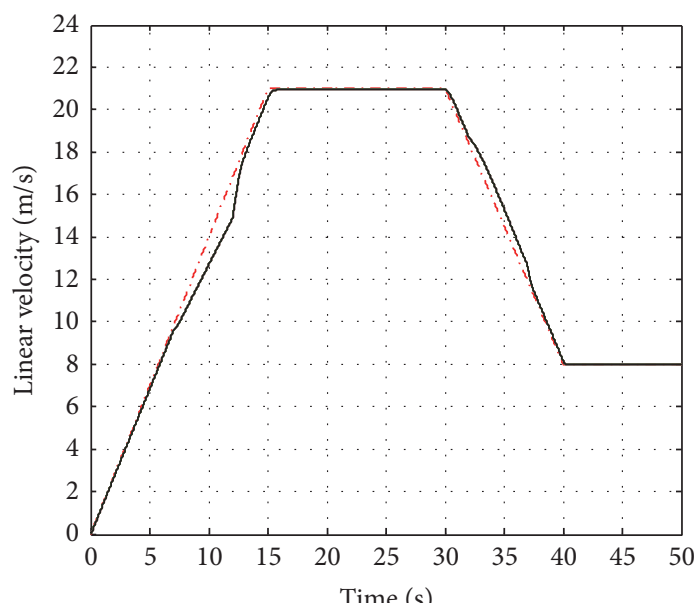

-. - Vehicle reference __ Rear right wheel

Vehicle velocity _ Front left wheel

— Front right wheel__ Rear left wheel

(a)

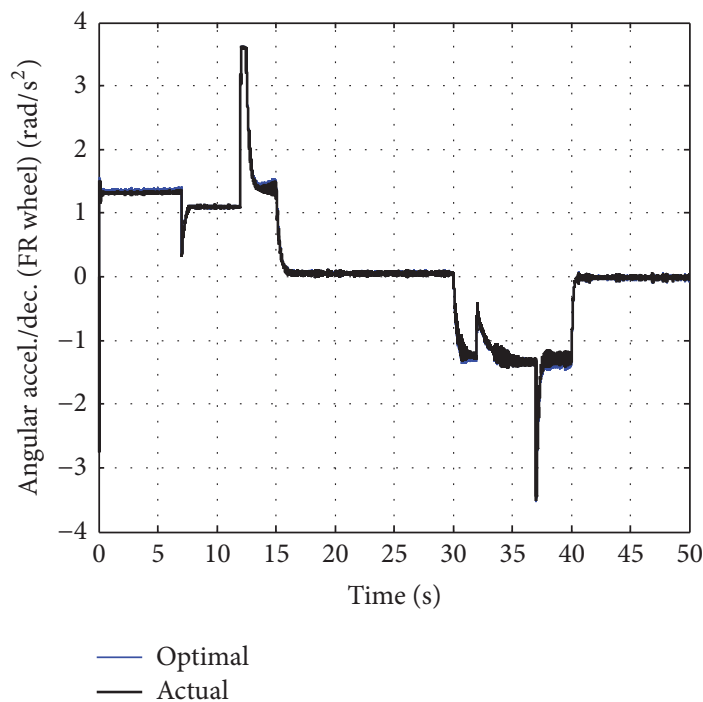

(c)

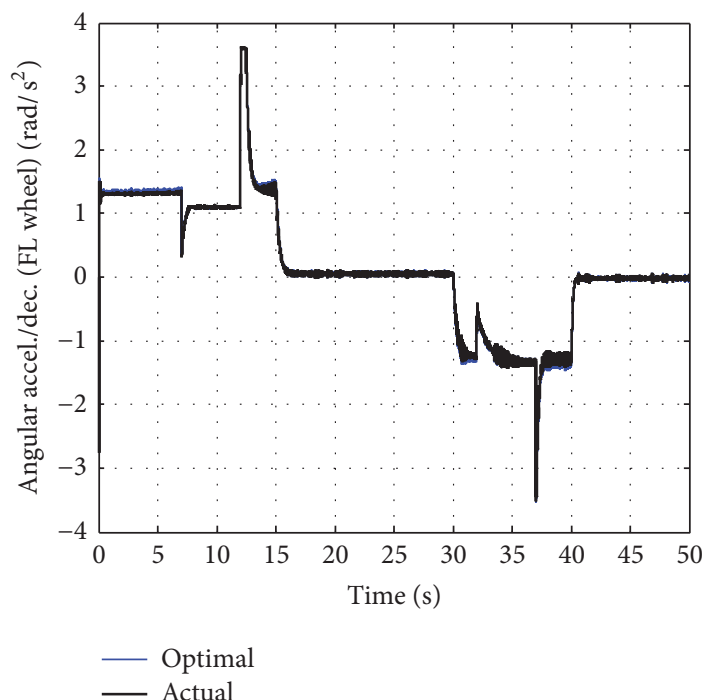

(e)

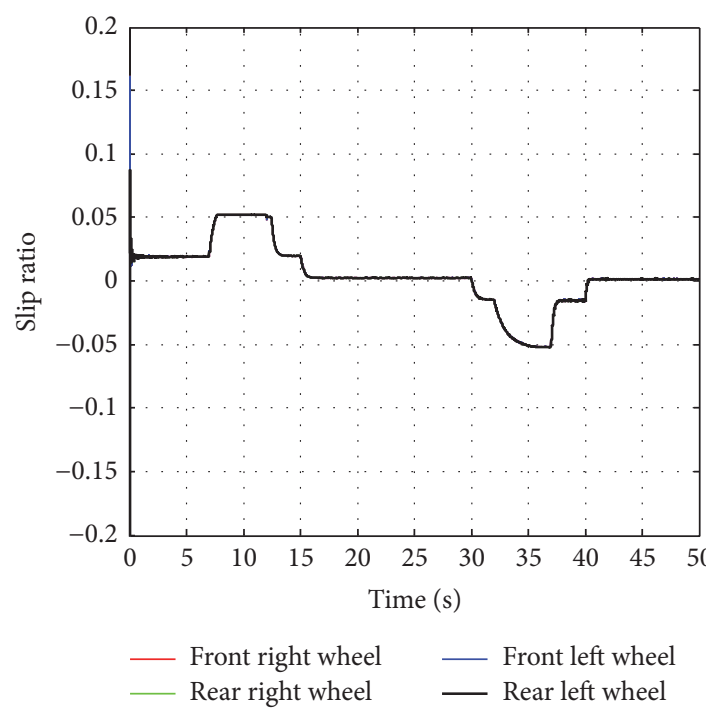

(b)

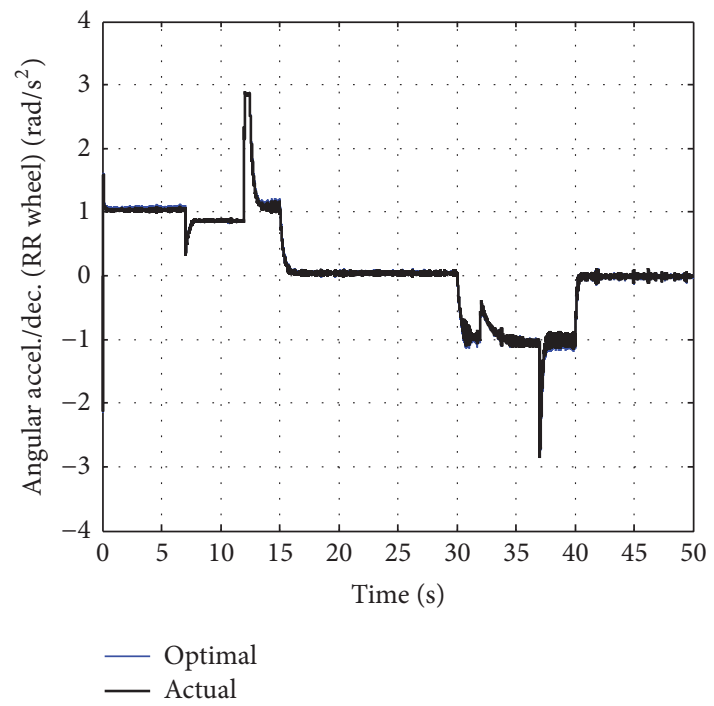

(d)

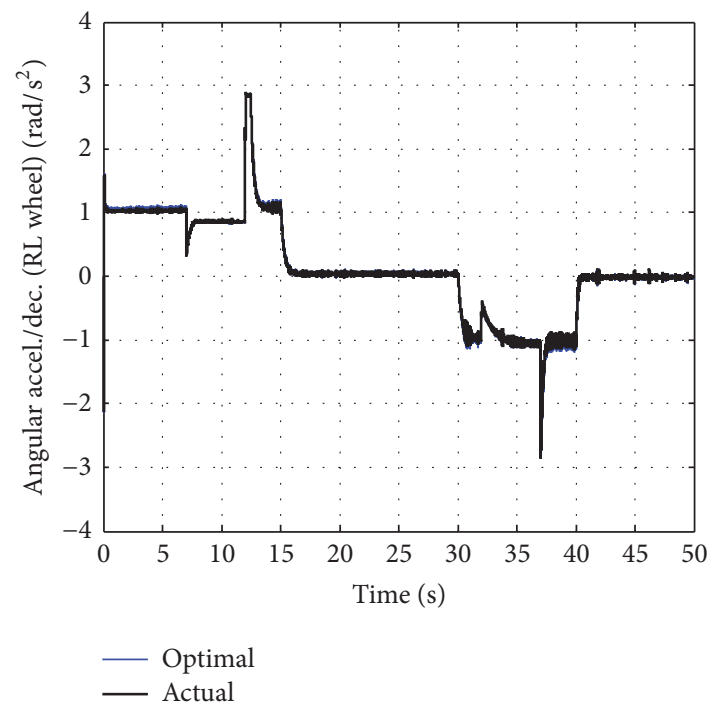

(f)

FIGURE 16: Continued. 

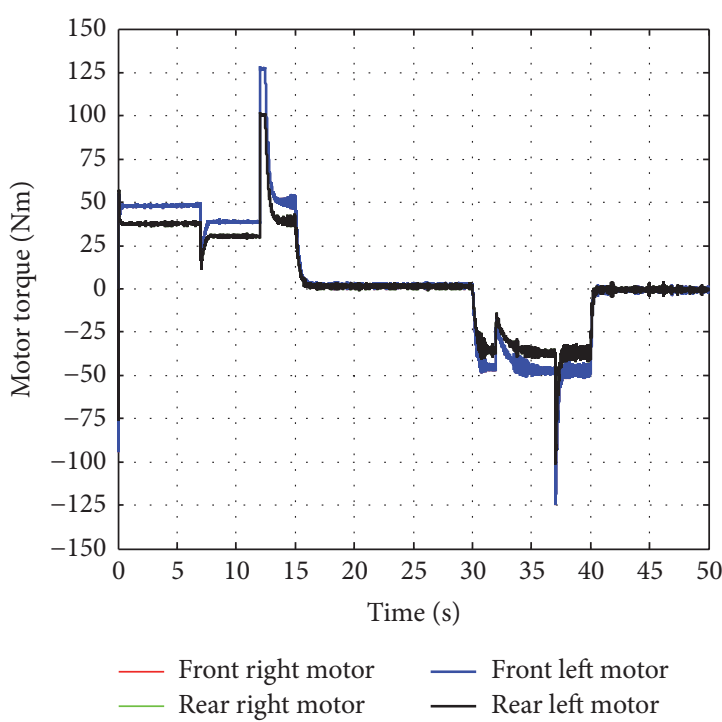

(g)

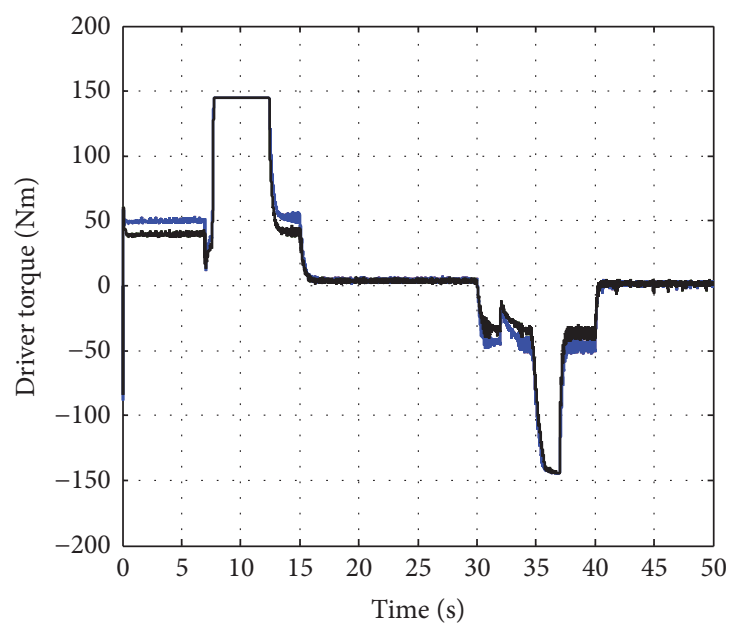

$\begin{array}{ll}\text { - Front right motor } & \quad \text { Front left motor } \\ \text { Rear right motor } & \quad \text { Rear left motor }\end{array}$

(i)

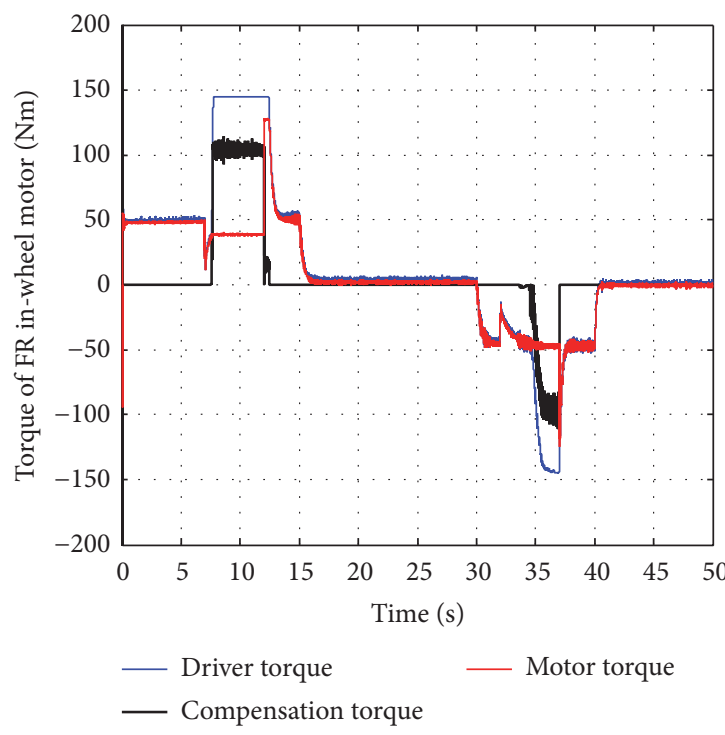

(k)

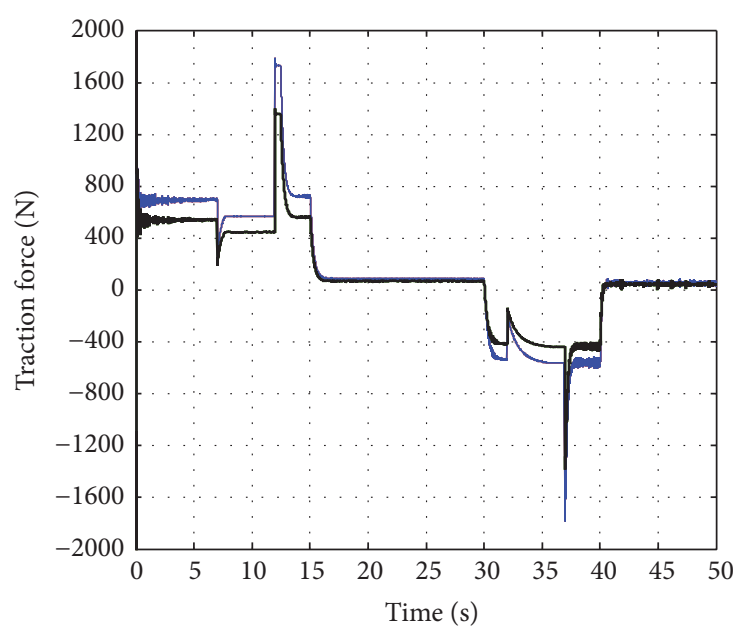

_ Front right wheel __ Front left wheel

(h)

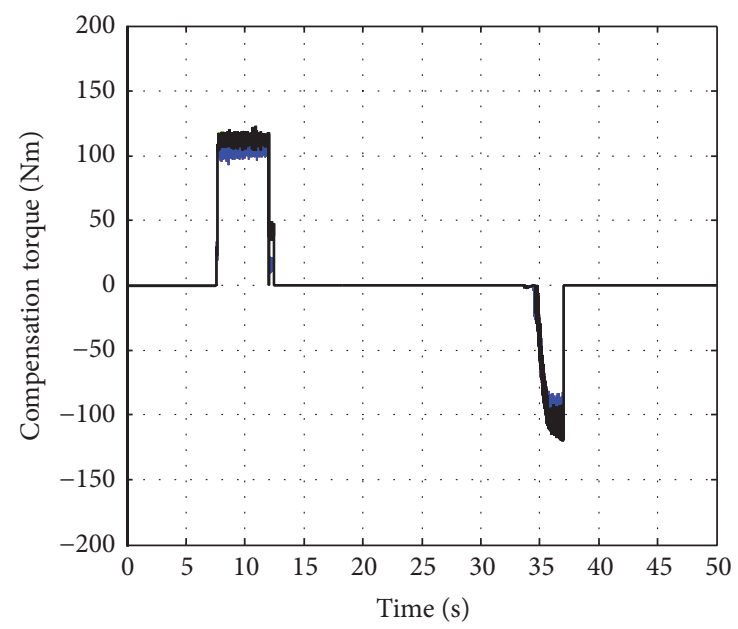

$\begin{array}{ll}\text { — Front right motor } & \text { Front left motor } \\ \text { Rear right motor } & \text { Rear left motor }\end{array}$

(j)

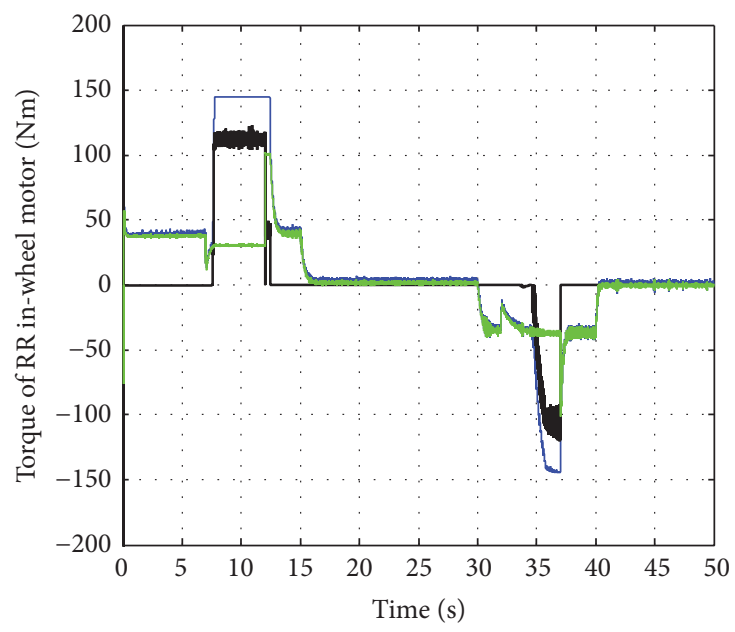

- Driver torque _ Motor torque

- Compensation torque

(1)

FIGURE 16: Continued. 


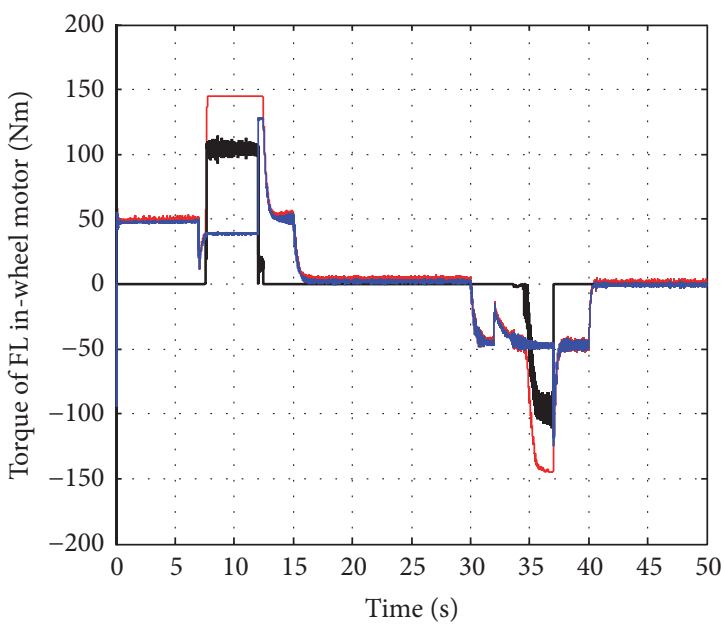

- Driver torque

- Compensation torque

— Motor torque

(m)

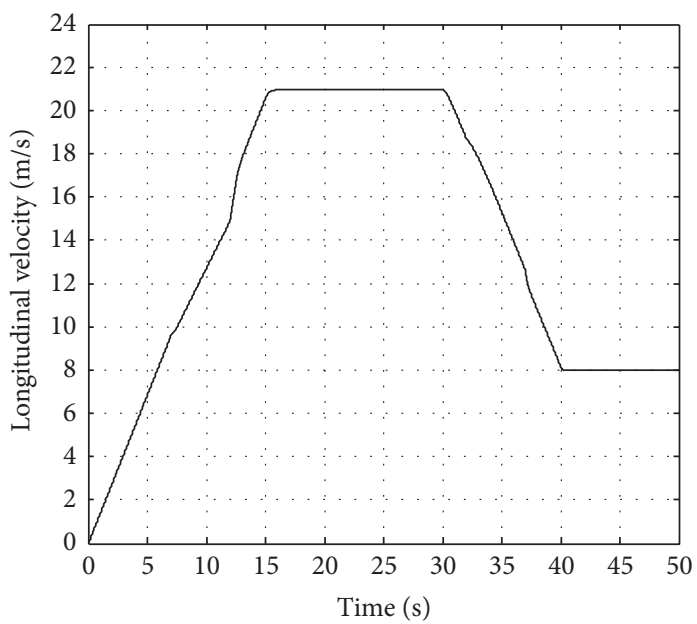

(o)

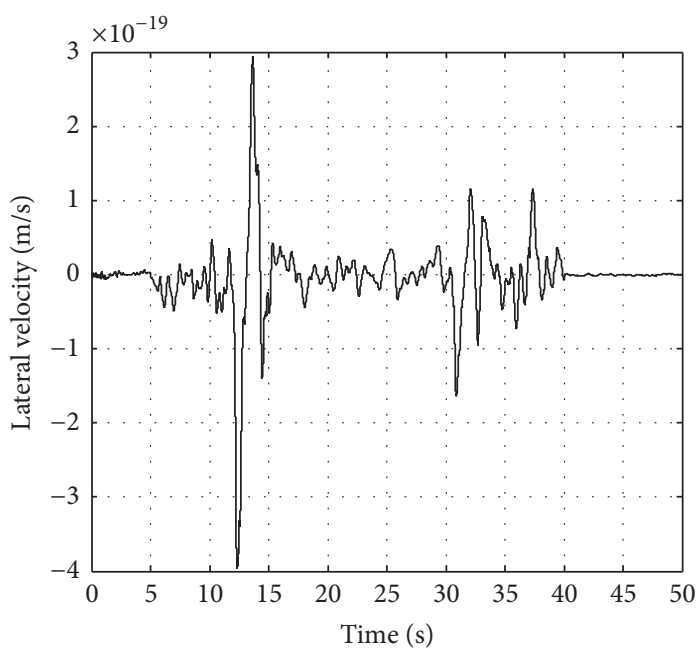

(q)

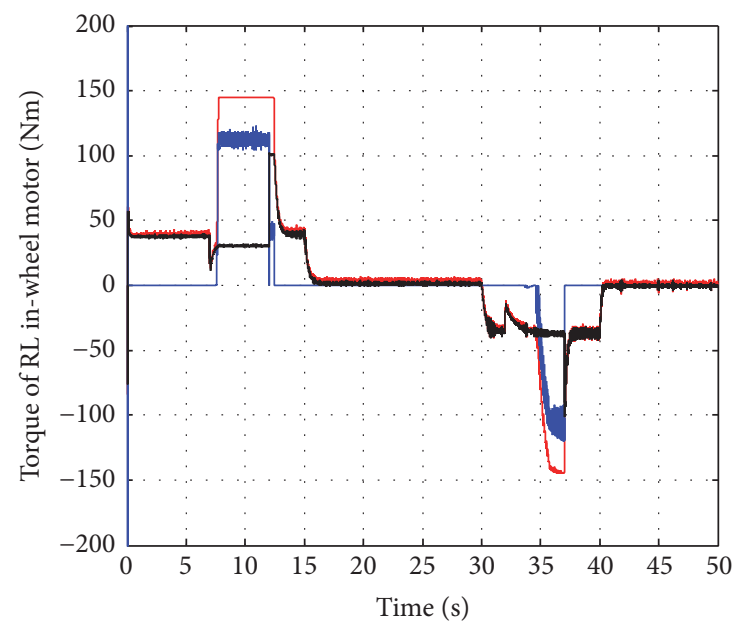

- Driver torque

- Compensation torque

— Motor torque

(n)

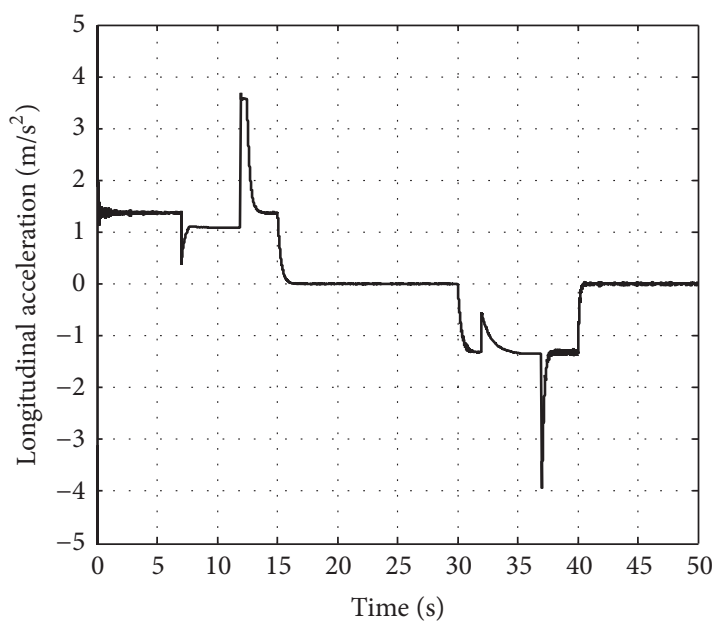

(p)

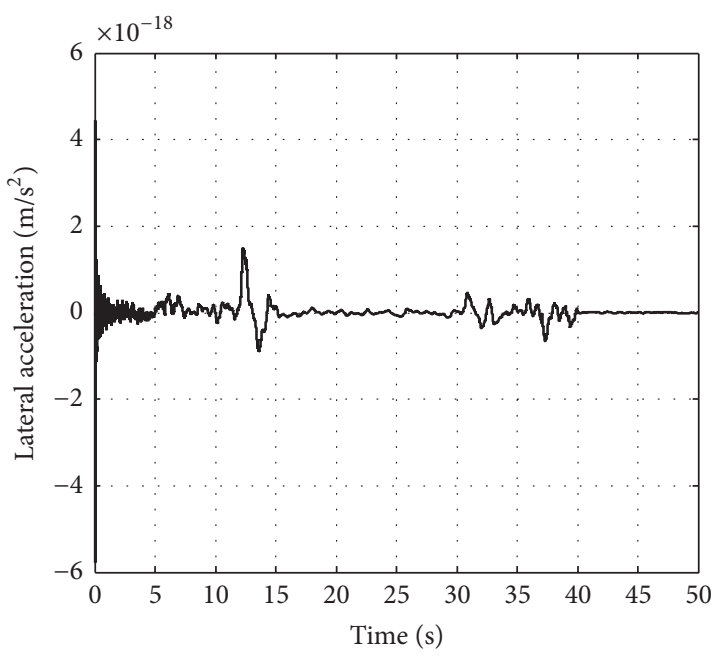

(r)

Figure 16: Continued. 


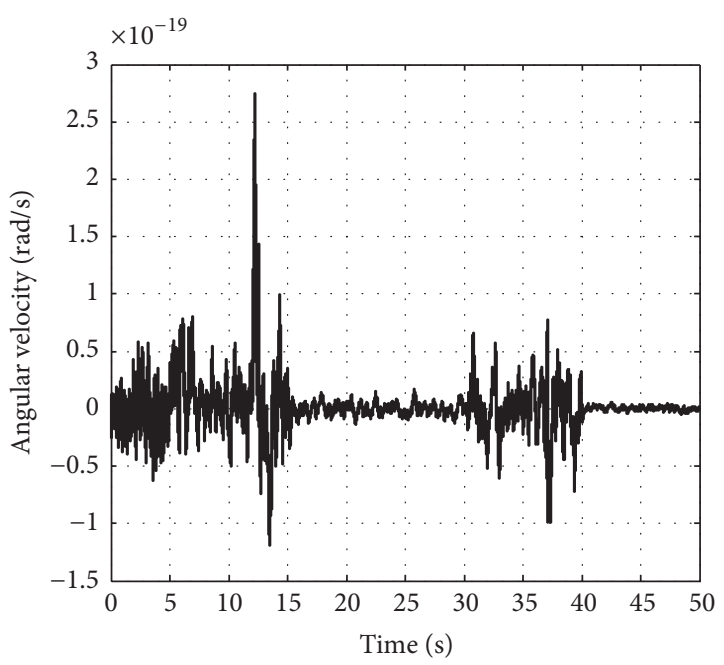

(s)

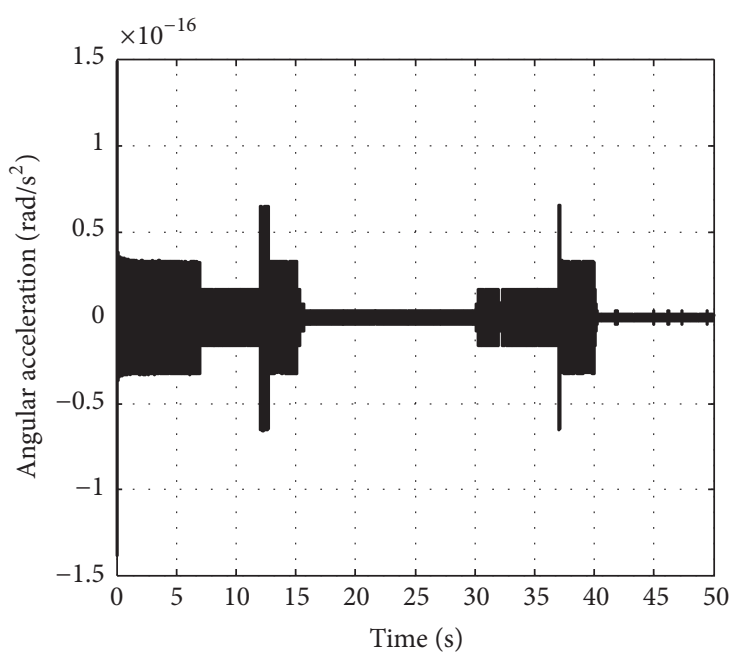

$(\mathrm{t})$

FIGURE 16: Simulation results of the EV driven under different road conditions.

16(g) and 16(i)-16(n)) and reduces significantly the angular acceleration errors. This would permit the readhesion of the wheels slipping and prevent vehicle slip. The variation of the motor torques is shown in Figure 16(g), and the imposed torques of the controller are shown in Figures 16(i)-16(n). As shown in Figure 16(h), the traction forces applied to the driving wheels have the same behavior during the loss of adherence.

In Braking Maneuver. The vehicle model will decelerate from $21 \mathrm{~m} / \mathrm{s}$ to $0 \mathrm{~m} / \mathrm{s}$ at 30 seconds, which lasts 10 seconds. The second loss of adherence of the four wheels starts at 32 seconds and lasts 5 seconds in this deceleration mode (Figure 15). The simulation results are also shown in Figure 16. In this maneuver, when the vehicle enters a slippery road, the longitudinal slip of the four wheels decreases rapidly, and the real longitudinal slip of each wheel is kept within the optimal longitudinal slip of -0.05 . It can be seen from Figures 16(b)-16(f) that the ABS control has realized smooth tracking of the wheel slip ratios, which have been maintained within the optimal range. Furthermore, it can also be seen in Figures 16(p), 16(r), and 16(t) that the ABS control produces no substantial oscillations of the vehicle deceleration, which can be considered as mainly beneficent from the viewpoint of the braking comfort in an electric vehicle. As shown in Figures 16(p), 16(r), and 16(t), the vehicle's acceleration performance is slightly affected under the skid phenomenon. Figure 16(a) shows that the difference between the vehicle speed and the in-wheel motors' speed is negligible. Moreover, it can be also seen from Figures 16(c)-16(f) that the difference between actual and threshold angular acceleration is close to zero, in both acceleration and deceleration modes used in the simulation, due to the proposed ASR/ABS control.

We notice that the NMP-DTC is an indispensable torque control in the proposed EV longitudinal control. The simulation results provide the evidence of improvements of the proposed NMP-DTC by indicating a fast torque response and an accurate speed tracking, even when the EV traction operates under acceleration maneuver and braking maneuver with the various conditions of adherence (see Figures 16(a), $16(\mathrm{~g})$, and $16(\mathrm{k})-16(\mathrm{o}))$.

Finally, by analyzing the simulation results on different road conditions, the proposed longitudinal control proves its robustness where the longitudinal slip ratio of each wheel can catch the optimal longitudinal slip ratio in a short time and the same results can be obtained as that in acceleration and deceleration modes.

\section{Conclusion}

In this paper, a new multimachine robust control for an electric vehicle longitudinal stability, based on nonlinear model predictive (NMP) direct torque control (DTC), was proposed. Moreover, NMP-DTC strategy has been improved by a fuzzy logic tuning algorithm, which generates online the weighting factors. As a result, the improved NMP-DTC precisely tracked the speed trajectory and guaranteed a high performance under variable load torques, which are similar to the EV-traction operations. The attention is focused on the coordinated acceleration slip regulation (ASR) and antilock braking system (ABS) functions, applied to the four permanent magnet synchronous (PMS) in-wheel motors in order to achieve a stable behavior of the wheels for various road conditions. The simulation results show that serious skids can be avoided with the proposed longitudinal control. It can enhance the driving performance and the stability of four-wheel driving independent electric vehicles.

\section{Notations}

\section{(1) The Specifications of Motors}

$R_{s}$ : Resistance, $0,03 \Omega$

$L_{s}$ : Inductance, $0,2 \mathrm{mH}$ 
$\Phi_{f}$ : Permanent magnet flux, 0,08 Wb

p: $\quad$ Pole pairs, 4.

(2) The Specifications of the Vehicle Used in Simulation

\author{
$M_{v}$ : Vehicle mass, $1562 \mathrm{~kg}$ \\ $J_{v}: \quad$ Vehicle inertia, $2630 \mathrm{~kg} \cdot \mathrm{m}^{2}$ \\ $J_{\omega}: \quad$ Wheel inertia, $1,284 \mathrm{~kg} \cdot \mathrm{m}^{2}$ \\ $L_{f}$ : Distance from the gravity center to the \\ front axle, $1,104 \mathrm{~m}$ \\ $L_{r}$ : Distance from the gravity center to the \\ rear axle, $1,421 \mathrm{~m}$ \\ $h_{c g}$ : Height gravity center of the vehicle, $0,5 \mathrm{~m}$ \\ $S_{f}$ : Frontal area of the vehicle, $2,04 \mathrm{~m}^{2}$ \\ $\rho: \quad$ Air density, $1,2 \mathrm{~kg} \cdot \mathrm{m}^{-3}$ \\ $C_{p x}$ : Drag coefficient, 0,25 \\ $C_{r r}$ : Rolling resistance coefficient, 0,01 \\ $C_{f}$ : Longitudinal stiffness of each tire, lateral, \\ $37407 \mathrm{~N} / \mathrm{rad}$ \\ $C_{r}$ : Lateral stiffness of each tire, lateral, \\ $51918 \mathrm{~N} / \mathrm{rad}$ \\ $R_{\omega}$ : Wheel radius, $0,294 \mathrm{~m}$.
}

\section{Conflicts of Interest}

The authors declare that they have no conflicts of interest.

\section{References}

[1] Y. Hori, "Future vehicle driven by electricity and control: research on four-wheel-motored 'UOT Electric March II,' IEEE Transactions on Industrial Electronics, vol. 51, no. 5, pp. 954-962, 2004.

[2] C. Ma, M. Xu, and H. Wang, "Dynamic emulation of road/tyre longitudinal interaction for developing electric vehicle control systems," Vehicle System Dynamics, vol. 49, no. 3, pp. 433-447, 2011.

[3] D. Yin, S. Oh, and Y. Hori, "A novel traction control for EV based on maximum transmissible torque estimation," IEEE Transactions on Industrial Electronics, vol. 56, no. 6, pp. 20862094, 2009.

[4] C. Geng, L. Mostefai, M. Denai, and Y. Hori, "Direct yawmoment control of an in-wheel-motored electric vehicle based on body slip angle fuzzy observer," IEEE Transactions on Industrial Electronics, vol. 56, no. 5, pp. 1411-1419, 2009.

[5] X. Liu, C. Ma, M. Li, and M. Xu, "A kriging assisted direct torque control of brushless DC motor for electric vehicles," in Proceedings of the 2011 7th International Conference on Natural Computation, ICNC 2011, pp. 1705-1710, July 2011.

[6] X. Liu, M. Li, C. Ma, and M. Xu, "Kriging assisted on-line torque calculation for brushless DC motors used in electric vehicles," in Proceedings of the 21st IEEE International Symposium on Industrial Electronics, ISIE 2012, pp. 1496-1501, May 2012.

[7] B. Long, S. T. Lim, J. H. Ryu, and K. T. Chong, "Energyregenerative braking control of electric vehicles using threephase brushless direct-current motors," Energies, vol. 7, no. 1, pp. 99-114, 2014.

[8] G. Xu, W. Li, K. Xu, and Z. Song, "An intelligent regenerative braking strategy for electric vehicles," Energies, vol. 4, no. 9, pp. 1461-1477, 2011.
[9] D. Zhang, G. Liu, W. Zhao, P. Miao, Y. Jiang, and H. Zhou, "A neural network combined inverse controller for a two-rearwheel independently driven electric vehicle," Energies, vol. 7, no. 7, pp. 4614-4628, 2014.

[10] J. Kang, J. Yoo, and K. Yi, "Driving control algorithm for maneuverability, lateral stability, and rollover prevention of 4WD electric vehicles with independently driven front and rear wheels," IEEE Transactions on Vehicular Technology, vol. 60, no. 7, pp. 2987-3001, 2011.

[11] L. Zhang, L. Li, C. Lin, C. Wang, B. Qi, and J. Song, "Coaxialcoupling traction control for a four-wheel-independent-drive electric vehicle on a complex road," Proceedings of the Institution of Mechanical Engineers, Part D: Journal of Automobile Engineering, vol. 228, no. 12, pp. 1398-1414, 2014.

[12] A. Pennycott, L. De Novellis, A. Sabbatini, P. Gruber, and A. Sorniotti, "Reducing the motor power losses of a four-wheel drive, fully electric vehicle via wheel torque allocation," Proceedings of the Institution of Mechanical Engineers, Part D: Journal of Automobile Engineering, vol. 228, no. 7, pp. 830-839, 2014.

[13] A. G. Ulsoy, H. Peng, and M. Çakmakci, Automotive control systems, Cambridge University Press, 2012.

[14] K. Hartani, M. Bourahla, and Y. Miloud, "New anti-skid control for electric vehicle using behaviour model control based on energetic macroscopic representation," Journal of Electrical Engineering, vol. 59, no. 5, pp. 225-233, 2008.

[15] K. Jalali, T. Uchida, J. McPhee, and S. Lambert, "Development of a fuzzy slip control system for electric vehicles with in-wheel motors," SAE International Journal of Alternative Powertrains, vol. 1, no. 1, pp. 46-64, 2012.

[16] W. Pasillas-Lépine, A. Loría, and M. Gerard, "Design and experimental validation of a nonlinear wheel slip control algorithm," Automatica, vol. 48, pp. 1852-1859, 2012.

[17] K. Hartani and A. Draou, "A new multimachine robust based anti-skid control system for high performance electric vehicle," Journal of Electrical Engineering and Technology, vol. 9, no. 1, pp. 214-230, 2014.

[18] R. De Castro, R. E. Araujo, and D. Freitas, "Wheel slip control of EVs based on sliding mode technique with conditional integrators," IEEE Transactions on Industrial Electronics, vol. 60, no. 8, pp. 3256-3271, 2013.

[19] L. Yuan, H. Chen, B. Ren, and H. Zhao, "Model predictive slip control for electric vehicle with four in-wheel motors," in Proceedings of the 34th Chinese Control Conference, CCC 2015, pp. 7895-7900, July 2015.

[20] C. Zhang, G. Yin, and N. Chen, "The acceleration slip regulation control for two-wheel independent driving electric vehicle based on dynamic torque distribution," in Proceedings of the 35th Chinese Control Conference, CCC 2016, pp. 5925-5930, July 2016.

[21] M. Sekour, K. Hartani, A. Draou, and A. Allali, "Sensorless fuzzy direct torque control for high performance electric vehicle with four in-wheel motors," Journal of Electrical Engineering and Technology, vol. 8, no. 3, pp. 530-543, 2013.

[22] K. Hartani, Y. Miloud, and A. Miloudi, "Improved direct torque control of permanent magnet synchronous electrical vehicle motor with proportional-integral resistance estimator," Journal of Electrical Engineering and Technology, vol. 5, no. 3, pp. 451$461,2010$.

[23] K. Hartani, M. Bourahla, Y. Miloud, and M. Sekour, "Electronic differential with direct torque fuzzy control for vehicle propulsion system," Turkish Journal of Electrical Engineering and Computer Sciences, vol. 17, no. 1, pp. 21-38, 2009. 
[24] G. H. B. Foo and M. F. Rahman, "Direct torque control of an IPM-synchronous motor drive at very low speed using a sliding-mode stator flux observer," IEEE Transactions on Power Electronics, vol. 25, no. 4, pp. 933-942, 2010.

[25] M. Preindl and S. Bolognani, "Model predictive direct speed control with finite control set of PMSM drive systems," IEEE Transactions on Power Electronics, vol. 28, no. 2, pp. 1007-1015, 2013.

[26] Y. Zhang and J. Zhu, "Direct torque control of permanent magnet synchronous motor with reduced torque ripple and commutation frequency," IEEE Transactions on Power Electronics, vol. 26, no. 1, pp. 235-248, 2011.

[27] Z. Huaqiang, W. Xinsheng, and W. Pengfei, "Study on direct torque control algorithm based on space vector modulation," Electric Machines and Control, vol. 16, pp. 13-18, 2012.

[28] S. G. Malla, M. H. L. Rao, J. M. R. Malla, R. R. Sabat, J. Dadi, and M. M. Das, "SVM-DTC permanent magnet synchronous motor driven electric vehicle with bidirectional converter," in Proceedings of the 2013 IEEE International Multi Conference on Automation, Computing, Control, Communication and Compressed Sensing, iMac4s 2013, pp. 742-747, February 2013.

[29] C. E. García, D. M. Prett, and M. Morari, "Model predictive control: theory and practice-a survey," Automatica, vol. 25, no. 3, pp. 335-348, 1989.

[30] M. Morari and E. Zafiriou, Robust process control, Prentice Hall, Englewood Cliffs, NJ, USA, 1989.

[31] R. Errouissi, M. Ouhrouche, W.-H. Chen, and A. M. Trzynadlowski, "Robust cascaded nonlinear predictive control of a permanent magnet synchronous motor with antiwindup compensator," IEEE Transactions on Industrial Electronics, vol. 59, no. 8, pp. 3078-3088, 2012.

[32] S. Li, K. Li, R. Rajamani, and J. Wang, "Model predictive multiobjective vehicular adaptive cruise control," IEEE Transactions on Control Systems Technology, vol. 19, no. 3, pp. 556-566, 2011.

[33] A. Bouscayrol, B. Davat, B. De Fornel et al., "Multi-converter multi-machine systems: Application for electromechanical drives," EPJ Applied Physics, vol. 10, no. 2, pp. 131-147, 2000.

[34] J. Chiasson, D. Seto, F. Sun, A. Stankovic, and S. Bortoff, "Independent control of two PM motors using a single inverter: Application to elevator doors," Proceedings of the American Control Conference, vol. 4, pp. 3093-3098, 2002.

[35] D. Bidart, M. Pietrzak-David, P. Maussion, and M. Fadel, "Mono inverter dual parallel PMSM - Structure and control strategy," in Proceedings of the 34th Annual Conference of the IEEE Industrial Electronics Society, IECON 2008, pp. 268-273, November 2008.

[36] K. Hartani, A. Merah, and A. Draou, "Stability enhancement of four-in-wheel motor-driven electric vehicles using an electric differential system," Journal of Power Electronics, vol. 15, no. 5, pp. 1244-1255, 2015.

[37] I. D. Landau, Adaptive Control: The Model Reference Approach, Marcel Dekker, New York, NY, USA, 1979.

[38] H. Pacejka, Tire and Vehicle Dynamics, Elsevier, 2005.

[39] M. C. Best, "Identifying tyre models directly from vehicle test data using an extended Kalman filter," Vehicle System Dynamics, vol. 48, no. 2, pp. 171-187, 2010.

[40] M. Terasaka, ABS control system, ed: Google Patents, 2012.

[41] G. Yin, S. Wang, and X. Jin, "Optimal slip ratio based fuzzy control of acceleration slip regulation for four-wheel independent driving electric vehicles," Mathematical Problems in Engineering, vol. 2013, Article ID 410864, 7 pages, 2013. 


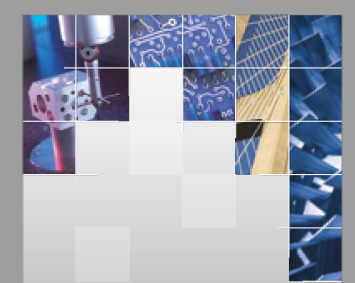

\section{Enfincering}
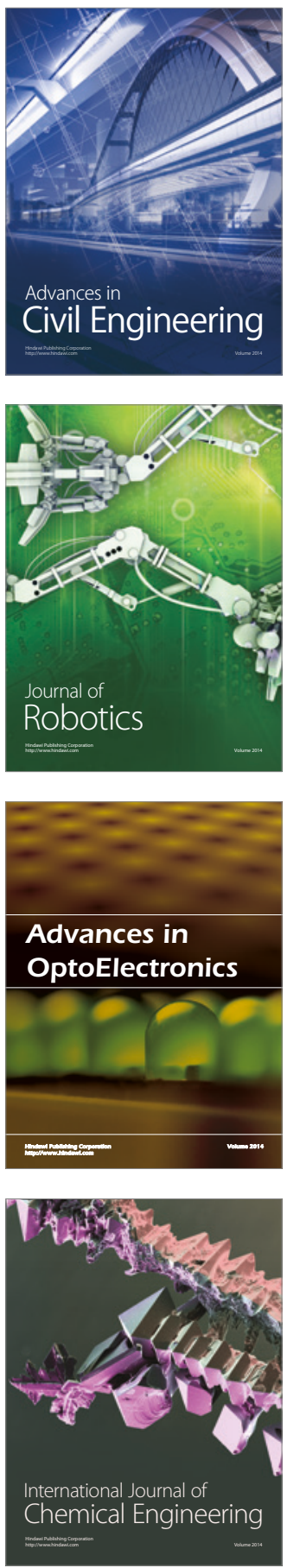

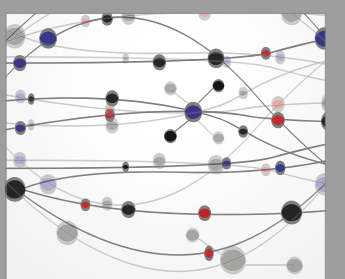

The Scientific World Journal

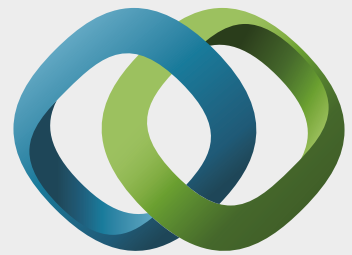

\section{Hindawi}

Submit your manuscripts at

https://www.hindawi.com
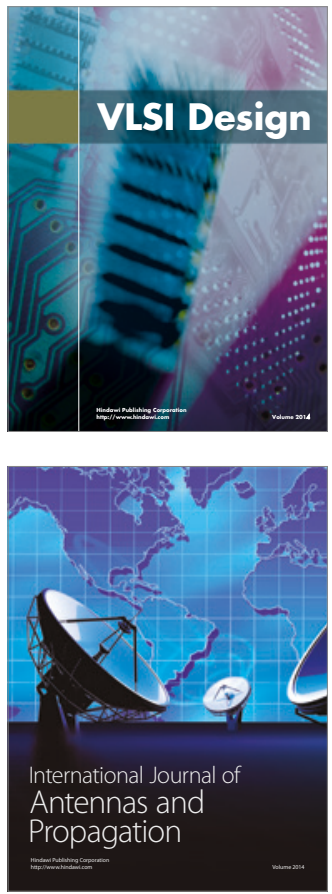

\section{Rotating}

Machinery
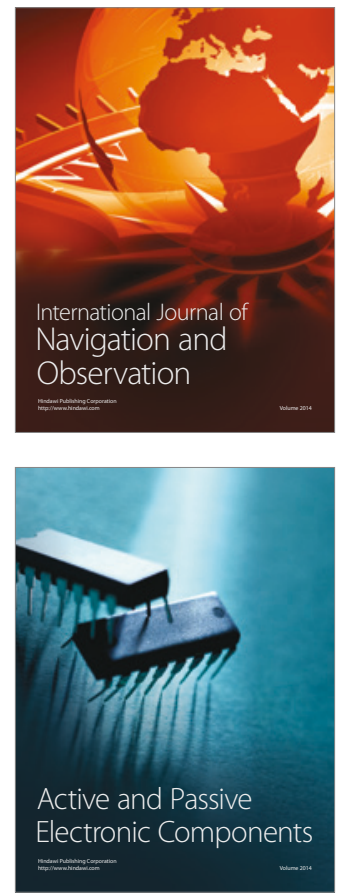
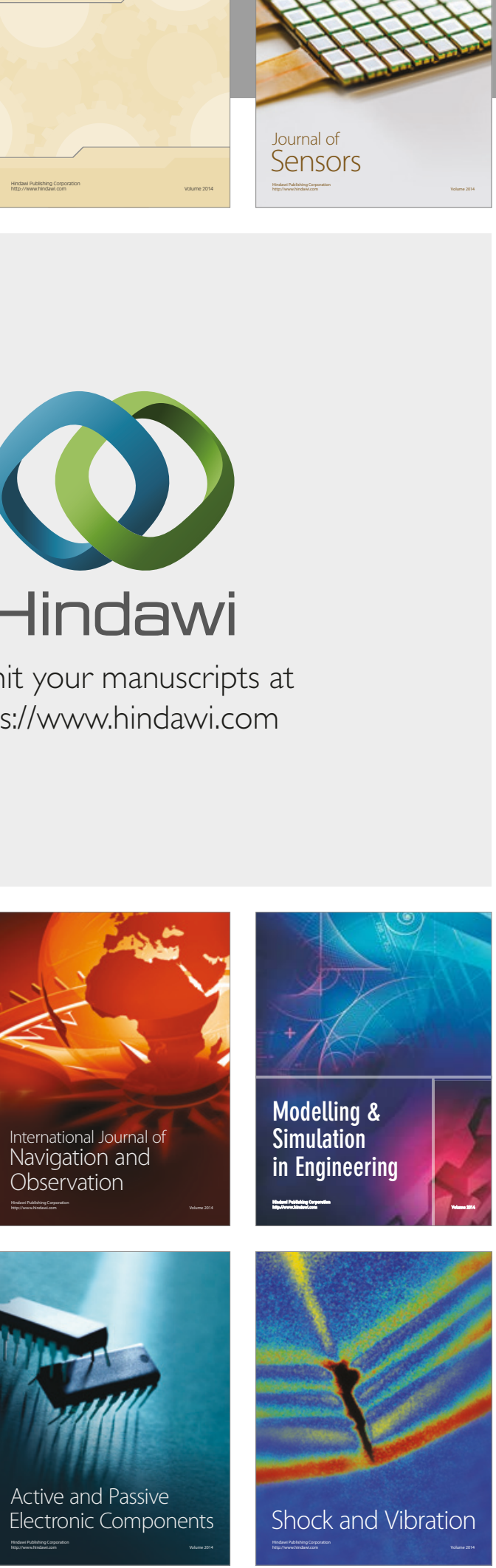
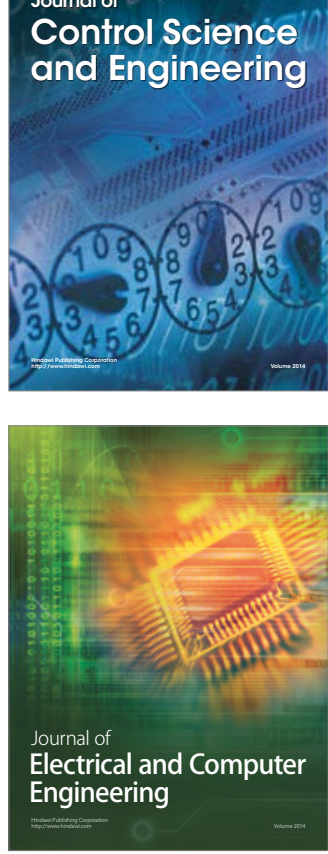

Distributed

Journal of

Control Science

and Engineering
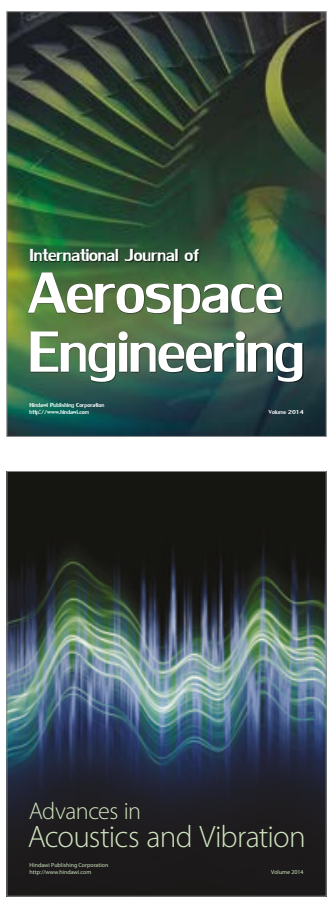

Sensor Networks 